\title{
Hornos, alfares y producciones cerámicas andalusíes en el entorno rural de Castellón de la Plana
}

\author{
Andalusian ceramic, kilns and pottery workshops in the rural area of Castellón \\ de la Plana \\ Josep Benedito Nuez* \\ José Manuel Melchor Monserrat ${ }^{\dagger}$
}

Fecha de entrega 9 junio 2020

Fecha de aprobación 15 junio 2020

\begin{abstract}
RESUMEN
Con este artículo no pretendemos ofrecer un panorama completo acerca de la investigación de los alfares andalusíes, lo cual resultaría imposible dada la gran cantidad de material que queda por investigar. Se trata más bien de introducirnos, a través de nuestras propias experiencias de campo, en el estudio de la cerámica y de los centros de producción que se implantaron en el territorio de Castellón de la Plana, que apoyamos en los descubrimientos más relevantes, con indicación de sus alfares, tipologías cerámicas, muestrarios ornamentales y alguna de las relaciones que tuvieron con otras cerámicas de la época.
\end{abstract}

Palabras clave: Castellón, Arqueología y Cerámica andalusí, Hornos, Tecnología, Centros de producción.

\section{INTRODUCCIÓN}

La nueva forma de hacer cerámica, que los musulmanes trajeron y difundieron por los territorios de la Península Ibérica, unida al extraordinario desarrollo de la ornamentación, sobre todo a partir de la incorporación de diversos óxidos colorantes, se ha documentado en numerosos yacimientos de al-Andalus. En lo relativo al reparto de talleres cerámicos, una de las concentraciones de hornos más interesantes se da en Córdoba, donde se han excavado más de un centenar de estas estructuras, seguida por otros hallazgos originales de Priego de Córdoba, Pechina (Almería), Málaga,

\begin{abstract}
Due to the large amount of existing Muslim ware items that still need to be examined, this study does not provide a complete overview of the research that has been conducted in this regard. Instead, the purpose of this paper is to present a study about the pottery, as well as the production centres located in the area of Castellón de la Plana, based on our self-experience in the field. Thus, the most relevant findings have been examined, including pottery workshops and typologies, ornamental samples and their connection with other ceramic elements of the time.
\end{abstract}

Keywords: Castellón, Archaeology and Andalusian Pottery, Kilns, Technology, Production centres.

Sevilla, Murcia, Denia, Valencia, Sagunto y también en Zaragoza o Balaguer (Lleida) (Fig. 1). Las noticias aportadas sobre el funcionamiento, tipología de los hornos, las distintas infraestructuras y el estudio de la producción cerámica procedente de estos centros productores ha experimentado un cambio trascendental gracias a los nuevos hallazgos. Estos descubrimientos están relacionados con las excavaciones que se han realizado en el barrio de San Cayetano de Córdoba (APARICIO, 2015); los talleres alfareros localizados en Sevilla (HERNÁNDEZ, 2014); los hornos de El Tolmo de Minateda, en Hellín, Albacete (GAMO, GUTIÉRREZ, 2009); los centros productores

* Universitat Jaume I de Castelló.

† Museo Arqueológico de Burriana. 


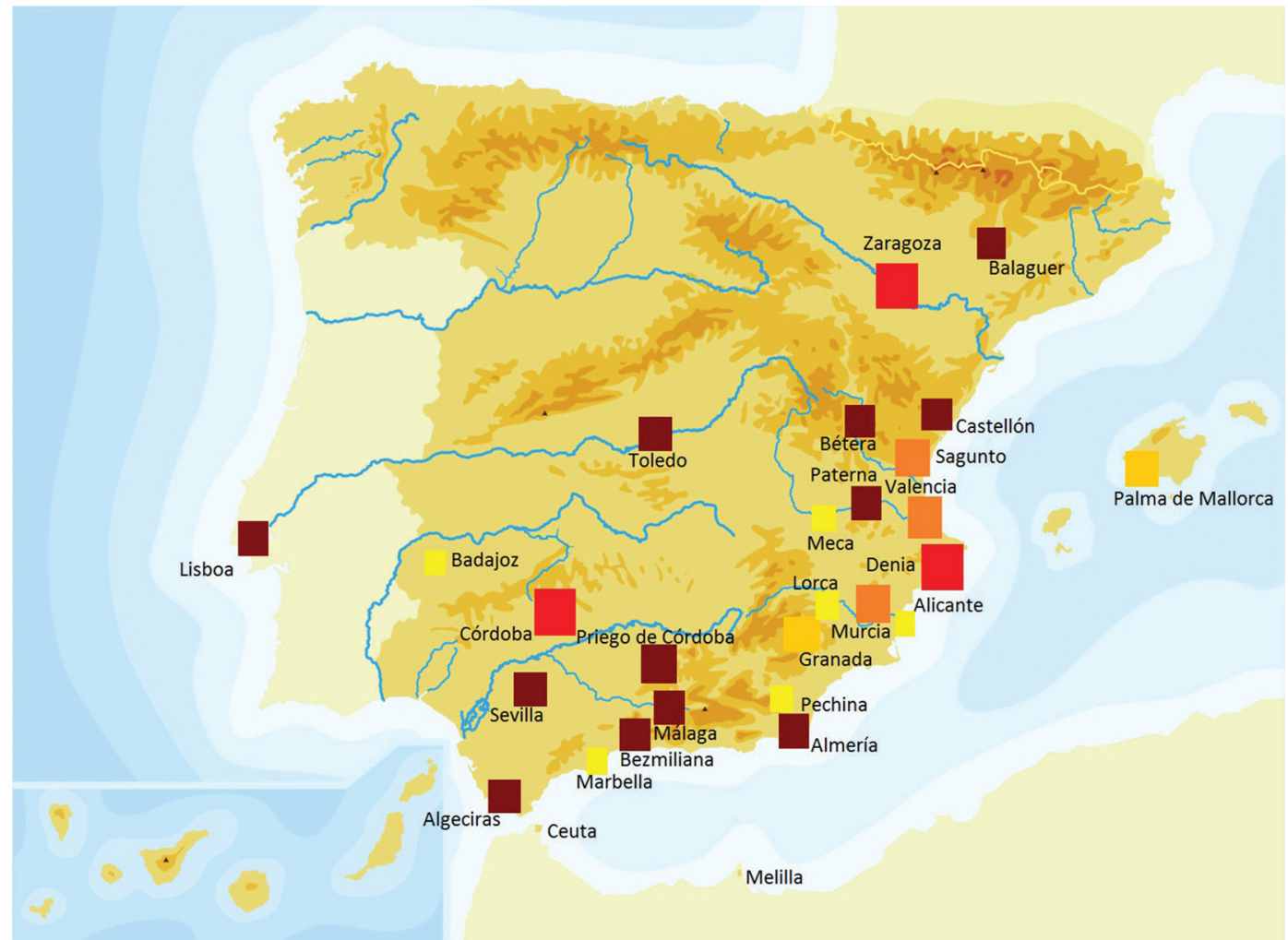

Fig. 1. Distribución de los hornos en al-Andalus a partir de la propuesta de Coll Conesa y García Porras (COLL, GARCIA, 2010). Rojo: más de 26 hornos; butano: de 11 a 25; oro: de 6 a 10; azafrán: de 2 a 5; amarillo: 1.

de Murcia (NAVARRO, JIMÉNEZ, 2009); el complejo alfarero de la calle Terrer Leonés y de la calle Álamo, esquina Lope Gisbert, de Lorca (CRESPO, GALLARDO, 2014); los alfares de Madinat Baguh, en Priego de Córdoba (CARMONA, LUNA, JIMÉNEZ, 2007); de Marroquíes Bajos, en Jaén (SALVATIERRA et alii, 2006); Algeciras (TORREMOCHA, 2015); los alfares de la calle San Pablo de Zaragoza (ESCUDERO, 20112012); los excavados en el Tossal de les Basses, Alicante (ROSSER, SOLER, 2015) y en la localidad de Sagunto (ASÓN, CARRERA, PERUA, 2010), entre otras intervenciones.

En el área valenciana el estudio de la cerámica andalusí ha adquirido un gran desarrollo gracias al aumento del número de publicaciones (GONZÁLEZ, 1952; GUICHARD, 1990; BAZZANA, 1990a; BAZZANA 1990b; BAZZANA, 1996; AMIGUES, 1985; GUTIÉRREZ, 1986; GUTIÉRREZ, 1988; GUTIÉRREZ, 1990-1991; GUTIÉRREZ, 1993; GUTIÉRREZ, 1995; AZUAR, 1985; AZUAR, 1989; AZUAR, 1998; AZUAR et alii, 1995; AZUAR et alii,
1997; AZUAR et alii, 1999; LERMA, 1990; LERMA et alii, 1990; SOLER, 1987; SOLER, 1988; SOLER, 1990; LÓPEZ, 1994; TORRES, 1995; PASCUAL et alii, 1997; PASCUAL et alii, 2009; COLL, 1989; COLL, 1998; COLL, 2009; COLL, 2014; COLL et alii, 1989; COLL, GARCÍA, 2010; entre otras). Las excavaciones arqueológicas, en este territorio, a lo largo de los últimos años han ido descubriendo singulares evidencias de talleres, hornos y restos de desechos de alfares que permiten que conozcamos mejor que hace unas décadas el proceso de elaboración de estas arcillas. Pero, ¿qué cerámica se manufacturaba exactamente en estas instalaciones? En los hornos se fabricaron con la técnica del bizcochado, es decir, la primera cocción a las que eran sometidas las cerámicas crudas, las vasijas de usos domésticos y culinarios como ollas y cazuelas, piezas básicas en la cocina andalusí, cuya forma respondía a las diversas preparaciones del alimento. Se elaboraron fuentes y ataifores, piezas de mesa, de presentación y consumo, más o menos grandes, y aptas para comer en 
común en torno a ellas. Redomas, piezas del servicio de mesa y contención de pequeñas cantidades de líquidos, como por ejemplo el vinagre. Formas de preparación de alimentos como marmitas, las más abundantes por su necesidad para la vida diaria, que solían ser usadas sobre un anafre o tannur. Jarritas y jarritos, tipos que eran habituales a la hora de las comidas conteniendo agua y otras bebidas. Tapaderas para acelerar la cocción, conservar el calor o sencillamente proteger el contenido. Tinajas, orzas, candiles, lámparas y arcaduces, alcadafes o lebrillos y trípodes. También se fabricó la loza estannífera, decorada en cobre, y en verde y manganeso. Loza barnizada y decorada en verde monocromo y azul turquesa, y la bizcochada con manganeso sobre melado. Mientras que otros talleres, más cualificados, produjeron cerámicas de las más ricamente decoradas: la cuerda seca total, la cuerda seca parcial y la cerámica esgrafiada. Con la incorporación de estas sofisticadas técnicas el repertorio formal se amplió e incluyeron originales jarritas, fuentes, bacines, cántaros, braseros, alcadafes, candiles y tapaderas, que aparecían profusamente ornamentadas. En las distintas excavaciones arqueológicas también se ha localizado una cantidad enorme de barras y trébedes, o atifles de tres brazos, usados para separar las vajillas durante la cocción, todos ellos realizados en barro cocido que se modelaban en abundancia debido a que tenían que reponerse constantemente. Además, es frecuente que cerca de estos centros se encuentren los testares a los que se arrojaba la cerámica defectuosa, que junto a los restos de la vajilla que aparece en el interior del horno nos proporciona un conjunto interesante de materiales para el conocimiento detallado y oportuno de su producción.

El horno es sin duda la estructura más compleja de un taller, que ha permitido la elaboración, la cochura que transforma el barro en terracota y finalmente el acabado de las cerámicas y piezas más refinadas que han salido a la luz en las excavaciones arqueológicas. J. Coll ha realizado una nueva visión de síntesis en favor de una interpretación más amplia acerca de las estrategias de producción de los complejos alfareros que se han localizado en la Comunidad Valenciana a lo largo de las tres últimas décadas (COLL, 2009; COLL, 2014). Por ejemplo, conocemos el caso de Denia, donde J. A. Gisbert localizó en 1985, al occidente del espacio extramuros de la medina, los primeros alfares y testares musulmanes del área levantina, sin duda alguna una de las evidencias arqueológicas más completas de lo que podemos considerar como un barrio alfarero de Šara al-Andalus (GISBERT, 1990; GISBERT, 1992; GISBERT, AZUAR, BURGUERA, 1991; GISBERT, BURGUERA, BOLUFER, 1992; 1995; AZUAR, 1989). Un horno alfarero se encontró en el solar de la Lonja de los Caballeros de la ciudad de Alicante, fechable en los siglos $X$ y XI, y restos de un testar en sus inmediaciones (COLL, 2009). Entre las calles Filet de Fora y Curtidors, en las afueras del recinto amurallado de Elche, aparecieron en 1995 restos de testares del siglo XI, de la primera época de Taifas, junto a otros de los siglos XII y XIII. En sus hornos se fabricaron varias formas de servicio de mesa (ataifores y alcadafes), contenedores para el agua (jarras, jarritas, jarritos y tapaderas) e iluminación (candiles de pie alto), y cocción (como anafes o fogones portátiles y marmitas), con decoraciones pintadas y esgrafiadas (AZUAR, MENÉNDEZ, 1997; AZUAR, 1998). De las estructuras del alfar, sin embargo, no se pudo documentar ninguna construcción. En el solar del colegio Julio Tena de Alzira se halló un conjunto de cerámicas que se consideraron desechos de alfar (MARTíNEZ PÉREZ, MARTÍNEZ RUIZ, 1990). El yacimiento fue sepultado a fines del siglo XI y no hay evidencias medievales de talleres cerámicos posteriores. En el Castellar de Meca de Ayora, en las excavaciones de los caminos que llevaron a cabo S. Broncano y M. Alfaro, aparecieron dos hornos para la cocción de pequeñas ollas realizadas a mano de los siglos X-XI (BRONCANO, ALFARO, 1997). En Valencia, en el año 1995 se excavaron las alfarerías del antiguo arrabal de l'Alcúdia, junto al camino de Sagunto, al norte del río Turia, que los arqueólogos fecharon entre los siglos X al XIII. Se halló un pozo para extraer agua, una balsa y un pocillo de decantación, cinco pequeñas estructuras de combustión y siete hornos más de planta oblonga, tres de ellos con banco o sagen (RUÍZ, GARCíA, 
1995). También se han hallado desechos de testar de época califal en el solar de los Baños del Almirante, en Valencia (AZUAR, 1985). En la localidad de Onda, concretamente en el testar de Mas de Pere (MONTMESSIN, 1980), se localizaron grandes cantidades de restos de alfarería pertenecientes a piezas bizcochadas, con una gran variedad formal de producciones que apuntan a una probable cronología califal. Por último, hay claras evidencias de producción cerámica en el alfar de la Partida de la Rosana, localizado al norte del río Palancia, en Sagunto (ASÓN, CARRERA, PERUA, 2010; ASÓN, CARRERA, 2016). Durante los trabajos arqueológicos salieron a la luz dieciocho hornos de época califal, un horno de época almohade y la estructura de los que pudo haber en el patio del taller o en el lugar de almacenamiento.

Además de estas evidencias que nos ha dejado la arqueología, las referencias a la documentación escrita, relativamente escasas, nos indican que probablemente existieron centros alfareros musulmanes en Xàtiva, Olocau, Llíria y Artana. También se ha afirmado que Paterna produjo alfarería musulmana, aunque no se conocen evidencias arqueológicas determinantes que demuestren la manufacturación cerámica antes de la conquista cristiana (COLL, 2009).

\section{LA ACTIVIDAD ALFARERA EN CASTELLÓN DE LA PLANA}

Existe un grave problema de conservación de los yacimientos arqueológicos que cuentan con estructuras especializadas en la producción de cerámica, lo que provoca que la localización de la mayoría de ellos se realice de forma casual, pues son descubiertos al realizar zanjas para la construcción de carreteras, nuevos proyectos urbanísticos o labores agrícolas. Esta circunstancia ha supuesto que gran parte de los hornos, en muchas ocasiones, hayan quedado destruidos y que el número de alfares excavados en Castellón sea reducido y en la gran mayoría de los casos se conozcan solo de manera parcial.

Los alfares han seguido unos patrones básicos para su ubicación, que en nuestro caso se repiten en todos los ejemplos. En primer lugar, se trata de lugares próximos a la materia prima básica, es decir, la arcilla que está presente en toda la llanura aluvial cuaternaria o cerca de las zonas pantanosas; es muy importante la cercanía a los cursos de agua: la séquia Almalafa y la séquia Major; la ubicación en un relieve abierto y poco accidentado; y, sobre todo, la proximidad a un territorio con abundante vegetación de bosque y sotobosque. Es lógico que los alfares estudiados se hallen contiguos a puntos de agua, precisamente esta proximidad ha dado lugar a la implantación de este tipo de asentamientos. En cuanto al combustible sería interesante averiguar las especies que presumiblemente fueron utilizadas en la combustión del horno para cocer las piezas, ya que dependiendo de la naturaleza de las mismas llega a variar en esencia y cantidad el calor y humo que producen, lo que como veremos también afecta al color de las cerámicas. Respecto al volumen de leña que se utilizaría en cada cocción, se ha establecido que para cada kilogramo de arcilla se necesitarían varios de combustible, por lo que era muy importante llevar a cabo estas actividades en zonas densamente pobladas en especies arbóreas. En este sentido, El Pinar del Mar de Castellón, El Pinar de l'Estepar y la zona de El Prat, o prado pantanoso inmediato, son las masas forestales más importantes en el entorno de estos yacimientos. Es conocida la absoluta dependencia que la sociedad medieval tenía del bosque y la regulación de los diferentes aprovechamientos del mismo para la obtención de leña, madera, carbón vegetal, resina, etc., a partir del siglo XIII, conforme aumenta el volumen de población en los núcleos rurales y las ciudades y se generalizan los conflictos para realizar los aprovechamientos (SORIANO, 2002). Además, junto a la arcilla son necesarios ciertos desgrasantes que se añaden a la misma para mejorar sus propiedades; éstos pueden ser de origen orgánico o tal vez minerales. Y, por último, también habrá que tener en cuenta aquellos óxidos susceptibles de ser utilizados como pigmentos en la decoración de la cerámica.

Existen otras particularidades que han condicionado el establecimiento de un alfar 
en estos lugares, aquí entra en juego conocer las vías de comunicación que existen en el entorno del alfar y que pondrían en relación estas instalaciones y las diferentes comunidades del entorno; en nuestro caso, los alfares se hallan muy próximos al trazado del Caminàs en un caso y del Camí dels Molins en el otro. Es fundamental también estudiar la demanda de los productos cerámicos, es decir, la población que adquiere estas manufacturas. Lo normal es que los alfares estuvieran emplazados relativamente alejados del núcleo poblacional y en un espacio totalmente abierto, pues necesitan grandes superficies para ubicar los testares donde retirar los desechos que producen, almacenar las materias primas y, por último, organizar los productos que allí se fabricaban.

Los alfares tuvieron un papel peculiar, pues en ellos se fabricó una cuantiosa producción de cerámica con tipologías, técnicas y series de gran gusto que, pese a no tener continuidad en la Edad Media, debieron de tener una clara influencia en los posteriores talleres cristianos de la región. A lo largo de la última década, varias excavaciones arqueológicas, de urgencia en su mayoría, han permitido el estudio de las soluciones adoptadas en la construcción de los hornos y, en algún caso, la recuperación y musealización de algunas de estas estructuras de cocción de cerámica andalusí, que hay que añadir al escaso panorama arqueológico que se conocía de esta época en la ciudad de Castellón.

A raíz de ello el estudio de estas estructuras ha despejado, en general, ciertas cuestiones relacionadas con las técnicas con las que fueron elaboradas, alguna de sus estrategias de implantación y comercialización de las cerámicas y, en el caso concreto de Castellón, aquellos aspectos relativos al proceso de desarrollo y posterior abandono de los espacios de asentamiento donde se construyeron, es decir, a las propias transformaciones que se sucedieron a partir del declive de estos establecimientos en la Baja Edad Media. Solo así se han podido hallar explicaciones acerca de los patrones de instalación de los centros de producción, de la evolución de estos establecimientos y de las redes de distribución y comercio de sus productos cerámicos.

Pero el estudio de los hornos de cerámica deja todavía en el aire una serie de interrogantes que surgen tras observar la distribución de las estructuras en el territorio que ocupa Castellón de la Plana, su tipología, la producción resultante y la distribución interna de los talleres alfareros, pues ello se manifiesta en la existencia o a veces ausencia de espacios de producción anejos, complementarios de los procesos de cocción y relacionados con los trabajos previos de almacenaje o preparación de la arcilla. En efecto, la localización de estos ambientes siempre ha resultado bastante compleja, puesto que las actividades propias de la alfarería no son proclives a proporcionar indicios o testimonios que permitan la reconstrucción arqueológica del proceso productivo más allá de los escasos restos que se conservan de los hornos.

Hasta aquí se han esbozado algunas de las carencias que existen en el estudio de conjunto de la cultura material andalusí en Castellón. Tras esta reflexión, cabe preguntarse a partir de ahora precisamente por el tipo de asentamientos que la arqueología ha documentado en su término municipal, y por las estrategias que siguieron los centros que se implantaron en estas tierras. Durante muchos años, la tendencia de los arqueólogos cuando encontrábamos fragmentos de cerámica musulmana, rápidamente ha sido la de no considerar otros tipos de yacimientos en el campo que no fueran alquerías (al-qurà), sin explicar a qué entidad de población nos estábamos refiriendo bajo dicho vocablo. En castellano es un término ambiguo que hace alusión a un lugar habitado en la zona rural, sin llegar a precisar los diferentes tipos de propiedad o las posibles categorías fiscales. Por tanto, en el caso concreto de Castellón de la Plana, podríamos pensar que los alfares tal vez estarían integrados en pequeñas qurà, es decir, en alquerías dependientes del hisn Hadral, el centro fortificado del distrito, como sabemos localizado en el Castell Vell o de la Magdalena. Pero si seguimos contemplando el rico mundo 
rural andalusí desde este esquema simple de husūn y qurà, difícilmente se podrán entender muchos otros matices económicos y la jerarquización administrativa de este territorio, así como las fluidas relaciones que existirían entre los diferentes espacios que lo componían, como por ejemplo la existencia de fincas dedicadas a la explotación del campo (maŷāšir), haciendas privadas de carácter aristocrático (riyād) o granjas (mazraea); y aunque resulta muy difícil conocer las verdaderas características del poblamiento que existiría en esta época, sabemos que en este territorio la sociedad se encontraba en un paulatino proceso de ruralización, pues se había generado un alto desarrollo del mundo rural, que sin duda debió reflejarse en el sistema económico y, por extensión, en las manufacturas cerámicas y sus estructuras de producción. La información de que disponemos actualmente en Castellón es bastante significativa, pero está llena de interrogantes por lo que se ha de decir que debemos tratar los datos con cautela a la hora de encasillar la realidad de estas tierras en época andalusí.

Respecto a las alfarerías, los restos más completos han sido hallados en la periferia, concretamente en las proximidades de la ermita de Sant Jaume de Fadrell, un antiguo núcleo de población andalusí que se sitúa al sur de la ciudad actual y a poco más de $3,5 \mathrm{~km}$ del mar. La otra alfarería que ha podido identificar la arqueología se halla en la partida de Safra, junto al riu Sec, es decir, al norte de la ciudad (Fig. 2). Ambos, Fadrell y Safra, son unos topónimos árabes que han pervivido en los documentos históricos hasta la actualidad. Pero la huella y presencia árabe en Castellón se puede constatar en otros nombres como Almalafa, Teccida, Beni Amargo, Benirabe, Benimucarra, Benifayren, Benimarra, Binafut y Binaçiet, que nos recuerdan el legado andalusí, la mayoría de los cuales perviven en nuestros días.

La investigación de la cerámica y talleres andalusíes en las tierras de Castellón ha alcanzado una destacada mejoría, que se ha recogido en algunas publicaciones que nos aportan interesantes novedades sobre todo a nivel cronológico, pues el estudio de ambos centros permite concebir cómo era la organización de unos talleres del periodo taifa y de los imperios africanos, que quizá también estuvieron en uso en la última fase califal (COLLADO, NIETO, 2008; CLARAMONTE, BENEDITO, MELCHOR, 2005 y 2008; ARMENGOL, 2013); si bien se trata de un avance todavía abierto sobre el que hay que seguir trabajando para completar las muchas lagunas que todavía hoy tenemos y, sobre todo, para trazar una panorama general preciso y detallado de lo que supuso realmente esta producción cerámica. Este trabajo ya se ha iniciado por algunos historiadores y arqueólogos, pero deberá apoyarse en el estudio de los materiales proporcionados por las nuevas excavaciones arqueológicas y en las muchas piezas que se encuentran todavía inéditas en los fondos y colecciones del Museo de Bellas Artes de Castellón.

\section{EL ALFAR DE FADRELL}

La existencia del alfar o taller de cerámica en este establecimiento viene definida a partir de la evidencia que supone el hallazgo de un horno de tiro vertical y planta circular, ejemplo paradigmático de cómo eran las estructuras de cocción en esta época. Ello junto a una serie de espacios anejos que hay que relacionar con la preparación y modelado de las arcillas que, sin embargo, como sabemos rara vez generan en la arqueología restos de estructuras visibles. Los testares, por su parte, son más fáciles de distinguir pues están formados por depósitos o acopios de numerosos fragmentos de cerámica que se ha desechado, y que presenta numerosos defectos. Estos montones de cerámica constituyen además un elemento claro que hay que vincular con las estructuras de cocción, pues pueden demostrar que los hallazgos sean contemporáneos a la existencia de un horno cerámico.

En este caso, el alfar encontrado en la partida de Fadrell se excavó durante las obras de la carretera de acceso al puerto de Castellón, a la altura del Caminàs, justo enfrente de la ermita de Sant Jaume de Fadrell. Las investigaciones realizadas hasta la fecha permiten 


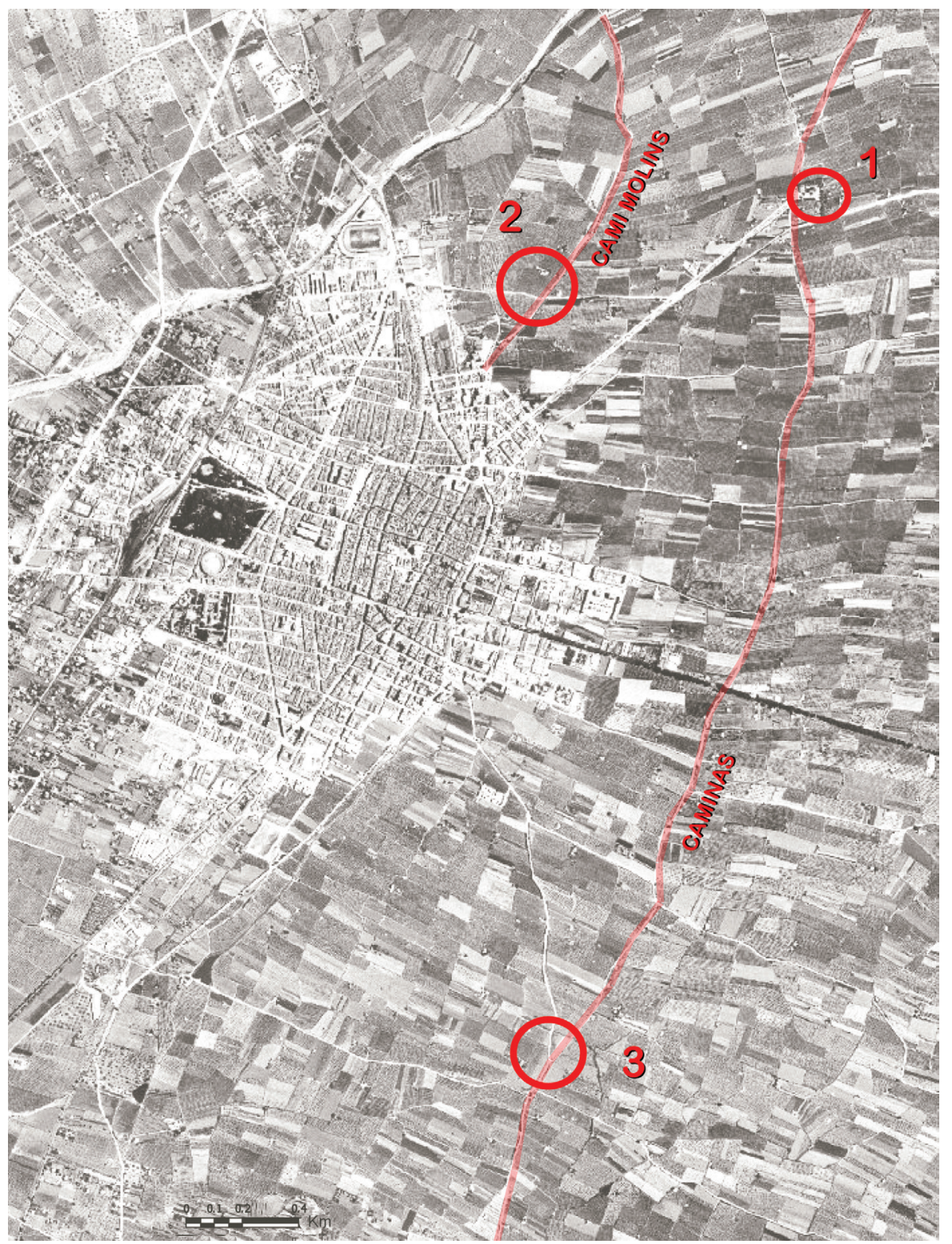

Fig. 2. Localización de los alfares de Lledó (1), Safra (2) y Fadrell (3), en Castellón de la Plana, sobre vuelo americano de 1945-46.

sugerir que en este lugar había probablemente una pequeña alquería musulmana (qarya), donde la torre defensiva (burŷ) pudo ser posteriormente absorbida por la construcción cristiana, pues la ermita se construiría hacia 1559. Sin embargo, J. Torró aporta una interesante novedad y cree que este asentamiento llegó a tener ciertos rasgos urbanos propios de una pequeña madina (TORRÓ, 2013).

Las excavaciones preventivas fueron realizadas por O. Collado y E. Nieto entre los años 2003 y
2004 y pese a que no llegaron a documentar restos arquitectónicos de relieve, sí que sacaron a la luz vestigios significativos de lo que había sido un poblado de llanura que reunía una importancia considerable, con un excepcional campo de silos.

La qarya de Fadrell se hallaba localizada muy cerca de la franja palustre, es decir, de la Marjalería, una extensa zona húmeda que se extendía a lo largo de $15 \mathrm{~km}$ de la costa, desde la sierra del Desert de les Palmes hasta la desembocadura del río Millars, incluyendo 
más de 2.000 ha (Fig. 3). La antigua población de Fadrell no llegaría a poner en cultivo estas zonas húmedas del litoral, pues sabemos que la desecación solo se realizó a través de la apertura de una acequia menor o canal de drenaje conocido como l'Escorredor de Fadrell (scurritorio quod dilabitur a Fadrell), hacia el cual se evacuaba el agua drenada de cada parcela por medio de zanjas o palafangues, que fue una obra de inicios del siglo XIV, es decir, inmediatamente posterior a la conquista. Su ubicación se asociaba al recorrido de la séquia d'Almalafa, un canal de riego independiente de la séquia Major, la principal acequia del sistema de irrigación andalusí de Castellón que deriva directamente de las aguas del Millars, y que también llegó a abastecer la qarya vecina de Vinamargo e incluso a la población de Almassora. Es evidente, pues, que solo tras la conquista se propiciaron los trabajos destinados a poner en cultivo el extremo sur del marjal, concretamente en el sector de las antiguas alquerías de Fadrell y Vinamargo (TORRÓ, 2010).

En el transcurso de las excavaciones se localizó la estructura de un horno cerámico realizado con barro desecado o adobes, cuya

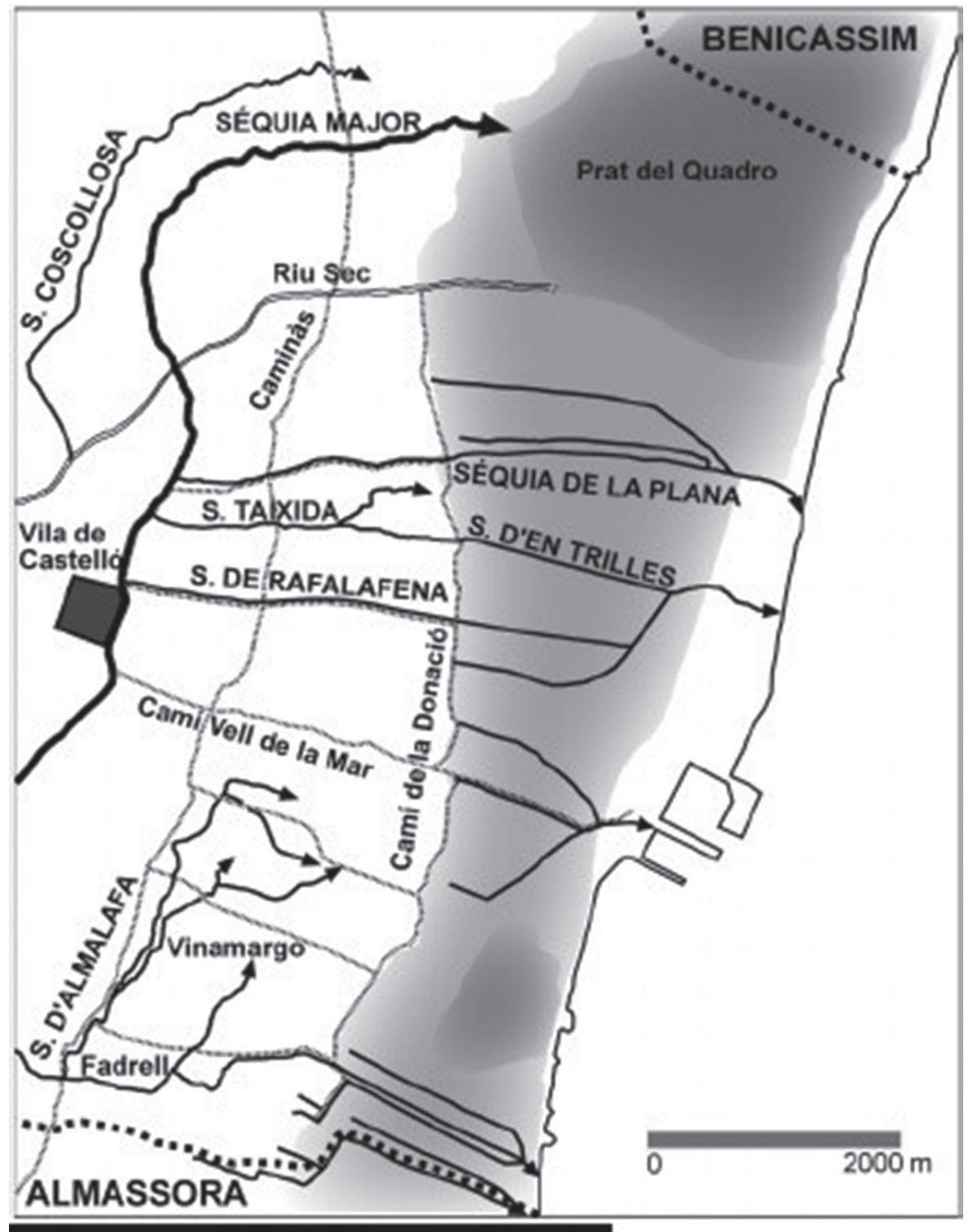

Fig. 3. Plano de las redes de drenaje de marjal de Castellón de la Plana (TORRÓ, 2010). 
planta de forma circular tenía un diámetro de aproximadamente unos dos metros. En su interior, durante los trabajos arqueológicos, se recogieron abundantísimos restos de "birlas" o rollos de alfarero y atifles, los restos de las paredes caídas de los laterales del horno, gran cantidad de fragmentos cerámicos de ataifores melados y un gran ataifor con decoración en manganeso. A lo largo de la excavación también se identificaron varias cubetas de extracción de arcillas que seguramente habrían sido utilizadas en la elaboración de los objetos cerámicos, junto a otras balsas propias de las labores alfareras. Por su parte, también se pudo recopilar información de muchos de los silos que se descubrieron junto al horno (Fig. 4), los cuales cumplían la función de vertederos, pues se hallaron colmatados con una cantidad ingente de restos cerámicos: grandes ataifores en verde y manganeso y ollas globulares, cazuelas, jarras, redomas y tinajas, materiales todos ellos que han sido fechados entre los siglos XII y XIII. La catalogación de estas estructuras anejas permite sugerir que dicho horno no fue en absoluto un elemento aislado en la época sino que habría formado parte de un conjunto de hornos similares que, construidos a la misma altura, no han podido ser localizados pues se hallarían en las parcelas inmediatas a la carretera.

Del horno solo se conserva la cámara de fuego, dotada de un bancal escalonado en la parte baja, habiendo desaparecido la cámara de cocción. En este caso se trata de un horno de barras o "birlas" de tipo vertical por lo que no debió de tener parrilla, es decir, era monocameral, estando unidas las cámaras de cocción y combustión. A partir de los restos de paredes del horno que se localizaron en su interior, las birlas, de ahí el nombre con que son conocidos, crearon una serie de filas de tubos integrados en la pared de la cámara de cocción, sobre las que se dispondrían las piezas ${ }^{1}$. Descritos

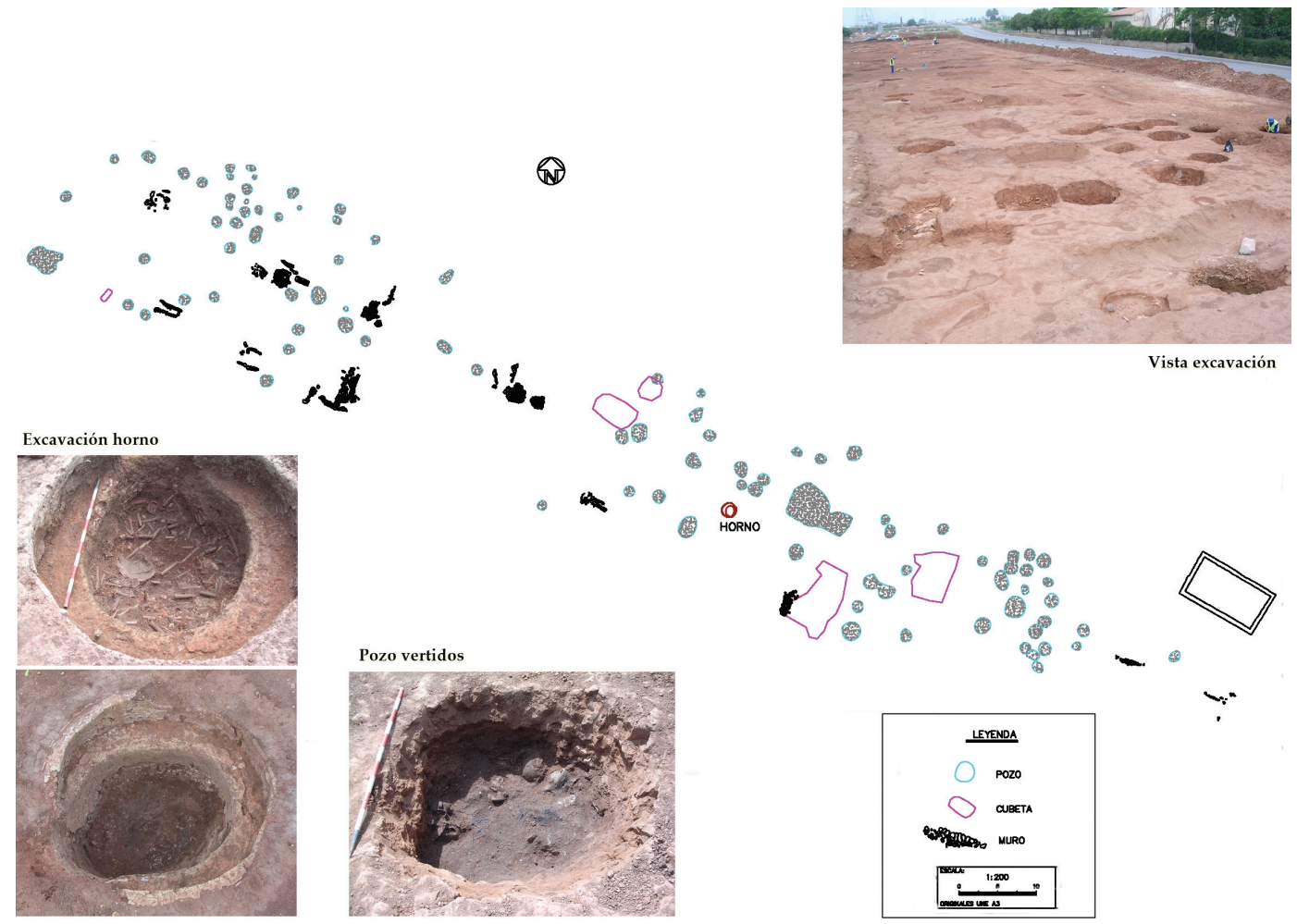

Fig. 4. Sant Jaume de Fadrell: dibujo en planta de la excavación del complejo alfarero y fotografías de la excavación, detalles del horno y de uno de los pozos de vertido con cerámicas (Planimetría y fotografías: Octavio Collado).

1. Queremos agradecer la colaboración de Octavio Collado, que nos facilitó la documentación sobre la excavación de Fadrell. 
en su día por J. Thiriot (THIRIOT, 1993), hornos de barras se han encontrado en todo el territorio de al-Andalus, aumentado notablemente su descubrimiento durante los últimos años debido a las intervenciones arqueológicas de urgencia. Encontramos paralelos de este tipo de hornos en las excavaciones del barrio alfarero de San Pablo y de Gómez Ulla de Zaragoza (MOSTALAC, 1990; AGUAROD, ESCUDERO, 1991; ESCUDERO, 2011-2012); Priego de Córdoba (CARMONA, LUNA, JIMÉNEZ, 2007); el complejo alfarero de las Ollerías (MOLINA, SALINAS, 2010) y de la plaza de la Lagunilla de Córdoba (RODERO, 2005); el casco urbano de Murcia (MUÑOZ, 1995); Denia (GISBERT, 2003); en el Pla d'Almatà de Balaguer (GIRALT, 1995); y en la Partida de la Rosana de Sagunto (ASÓN, CARRERA, 2016), entre otros ejemplos. Cronológicamente se utilizan desde época califal y su uso continúa durante la etapa almohade.

Bajo el trazado de la actual carretera, junto a la ermita, se localizaron más de cien silos y una fosa que ahondaba hasta una cota de 2,30 $\mathrm{m}$, con un perfil abovedado, que los arqueólogos piensan que podría tratarse de un aljibe o depósito destinado a guardar agua potable (COLLADO, NIETO, 2008). En el fondo, debajo de la tapadera, apareció la cerámica más excepcional de todas las halladas en la excavación: un ataifor realizado en cuerda seca total con decoración zoomorfa, un caballo profusamente decorado sobre cuya grupa se encuentra un ave con las alas explayadas, que reseñamos en el último apartado del artículo. Este magnífico plato está expuesto en las vitrinas del Museo de Bellas Artes de Castellón y constituye el mejor indicio de la riqueza y de las conexiones comerciales de este asentamiento con los otros enclaves andalusíes de la costa mediterránea.

Los otros restos localizados en la excavación corresponden a muros muy mal conservados, elaborados la mayoría con mampuesto de barro, alguno de los cuales habría que interpretar como habitaciones pertenecientes al alfar. Otros de los muros habría que ponerlos en relación con las viviendas en esta misma zona y que, por tanto, habría que vincular también con los enterramientos localizados al otro lado de la carretera, junto a la actual ermita.

\section{LOS ALFARES Y TESTARES DE LA ALQUERÍA DE SAFRA}

La relevancia de este nuevo yacimiento, productor de cerámicas, queda patente a partir de las excavaciones arqueológicas que se realizaron entre los años 2001 y 2003, y que nos han proporcionado interesantes vestigios que permiten reconstruir cuatro hornos y la organización de varias estancias de uno o probablemente varios talleres cerámicos (CLARAMONTE, BENEDITO, MELCHOR, 2008). Todo ello indicaba la creación de un espacio industrial al nortey en la periferia del territorio de Castellón, agrupándose en ambos márgenes del Camí dels Molins, para el propio abastecimiento alfarero de unas comunidades andalusíes que se hallaban en continuo crecimiento. Los hornos eran de doble cámara y parrilla perforada, es decir, el tipo más habitual en época andalusí. Son de tiro directo y doble cámara, la inferior o de cocción se excavaba en profundidad, solía ir precedida por un espacio para su alimentación y se abría al exterior mediante un arco por el que el alfarero controlaba el fuego. Era donde se realizaba la combustión, aunque en ocasiones se usaba también para cocer cuando existía un banco (sagen). La cámara superior se separaba de la baja por un piso perforado o parrilla, que constituía el suelo del laboratorio donde se disponían las cerámicas. La estructura estaba provista de una puerta de carga, se cerraba por muros de adobe o tapial y se remataba con una bóveda con varias aperturas de tiro y, a veces, una simple cubierta plana. Se trata de un tipo de hornos directamente heredados de los modelos elaborados por los romanos, que con algunas variantes se repite en todo el mundo islámico. El horno de doble cámara y bóveda supuso, en la época, un gran avance en el sistema de cocción al ser estructuras que aprovechaban mejor el laboratorio, ya que podían albergar más piezas, aproximadamente unas doscientas, y además mejorar el control de la temperatura, regular la distribución del calor y la posibilidad de 
usarlo tanto para cochuras oxidantes, combinadas con oxígeno, como reductoras; cuando entraba más combustible que oxígeno el horno se llenaba de humo, por lo que las chimeneas de la bóveda podían abrirse o cerrarse a conveniencia.

Se descubrieron también las tenues trazas de ocupación de estos espacios, formadas en su mayoría por encajes de poste, capas arcillosas, recortes en el terreno y en algunos casos pequeñas cubetas, que quizás reflejan los residuos de una preparación sencilla de la pasta. Los talleres alfareros se ubicaban en una zona por la que discurría la séquia Major, hoy en día canalizada, y donde abundaban las arcillas aluviales cuaternarias.

Durante la intervención arqueológica también se recuperaron varios silos colmatados con tierra y cerámica, entre cuyos fragmentos hay que destacar la presencia de algunas piezas deformes y defectuosas (Fig. 5). La excavación contribuyó, por tanto, al estudio de este tipo de estructuras y de varios complejos alfareros, cuyo número total sin embargo desconocemos pues no se excavaron todas las parcelas.

Los primeros trabajos se llevaron a cabo en la zona correspondiente a la calle Calderón de la Barca, donde se descubrieron dos hornos destinados a la fabricación de cerámica. El hallazgo se produjo justo en el margen izquierdo del Camí dels Molins. El terreno

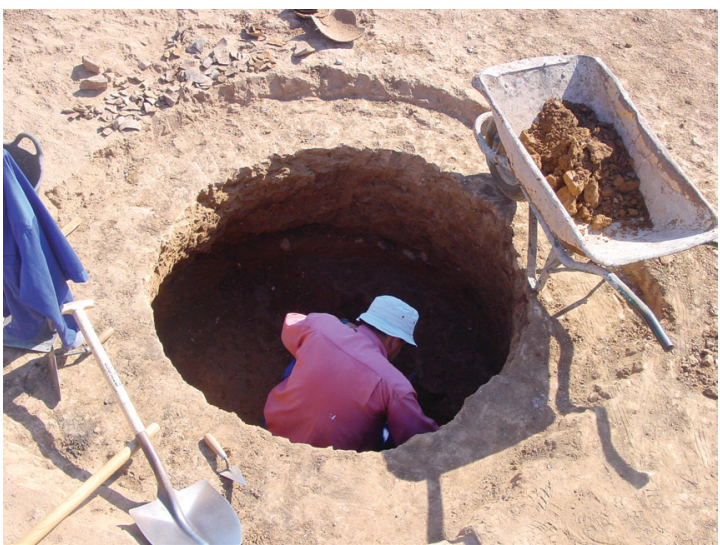

Fig. 5. Alquería de Safra: excavación de uno de los silos, junto al Cami dels Molins. presentaba manchas de cenizas, tierra de color oscuro característica de contextos con gran contenido de materia orgánica, muchas piedras y gran cantidad de cerámica. La construcción de cada uno de estos hornos se inició con la excavación de la cámara de combustión en el terreno natural.

El primer horno se encontró parcialmente destruido, pues la solera o parrilla tendió a desplomarse a consecuencia del uso continuado al que se había visto sometido (Fig. 6). El principal problema de este tipo de estructuras es la debilidad de las parrillas, que a consecuencia de las cocciones sucesivas a menudo se hundían por el peso de la carga. En estos casos se optaba por distintas estrategias de reparación antes de la amortización y abandono definitivo del horno. En Safra debió ser frecuente la reparación de las parrillas construyendo unas columnas en el interior del hogar para el sostenimiento de la solera, construcción que sabemos que se usó muy frecuentemente a lo largo de la época andalusí (COLL, GARCÍA, 2010) (Fig. 7).

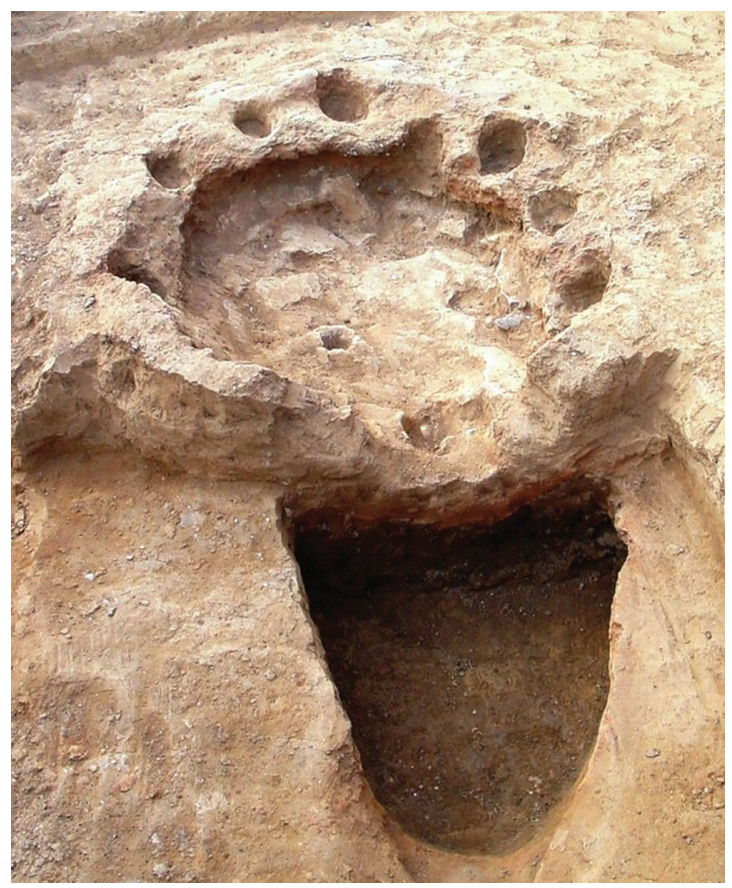

Fig. 6. Alquería de Safra: detalle del primer horno que se localizó en la excavación de la calle Calderón de la Barca. En este caso, la parrilla del horno se hundió a consecuencia de un uso prolongado de la estructura. 


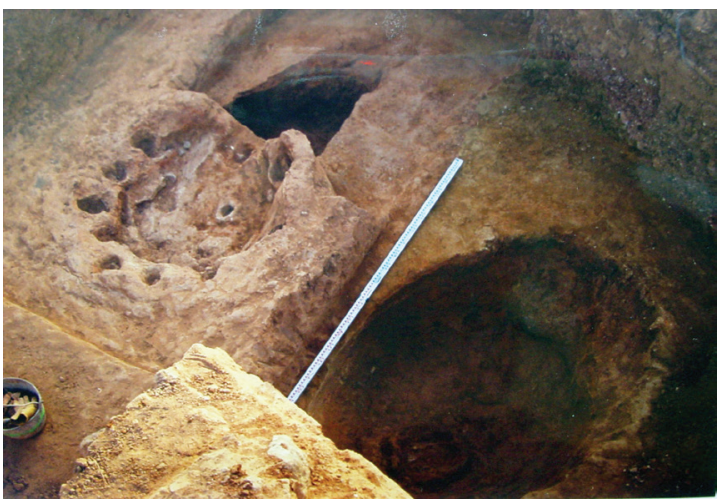

Fig. 7. Alquería de Safra: excavación de los hornos de la calle Calderón de la Barca. Era frecuente la construcción de columnas en el interior del hogar para el sostenimiento de la parrilla, taly como se observa en la cámara de fuego situada a la derecha de la fotografía.

La excavación de esta estructura resultó ser muy interesante, pues se pudo documentar al detalle cada uno de los estratos que colmataban el interior del horno. El primero de ellos estaba compuesto por el derrumbe de las paredes de adobe del laboratorio, cascotes de arcilla, junto a una gran cantidad de fragmentos de cerámica, piedras, carbones y cenizas. A continuación, se registró el nivel perteneciente al derrumbe de la parrilla de cerámica del horno; y, por último, por debajo de este derrumbe, apareció el nivel de relleno de la cámara de combustión, formado por una arena muy compacta, adobes, carbones, cenizas y una gran cantidad de fragmentos de ollas que presentaban defectos de cocción, todos de pasta reductora, es decir, de color gris y negro. La totalidad de piezas cerámicas quemadas pertenecía, por tanto, a la misma hornada.

Los restos del horno muestran una estructura de planta circular de casi dos metros de diámetro y poco más de un metro de profundidad. La longitud total del horno es de 2,50 m, de ellos $92 \mathrm{~cm}$ corresponden a la boca de la caldera. Cuando se descubrió, conservaba buena parte de la solería horadada que llegó a ocupar casi todo el hueco de la cámara de fuego. Su construcción se orientó de forma perpendicular al Camí dels Molins y con la boca de la caldera orientada al camino. La solería presentaba las perforaciones circulares, un

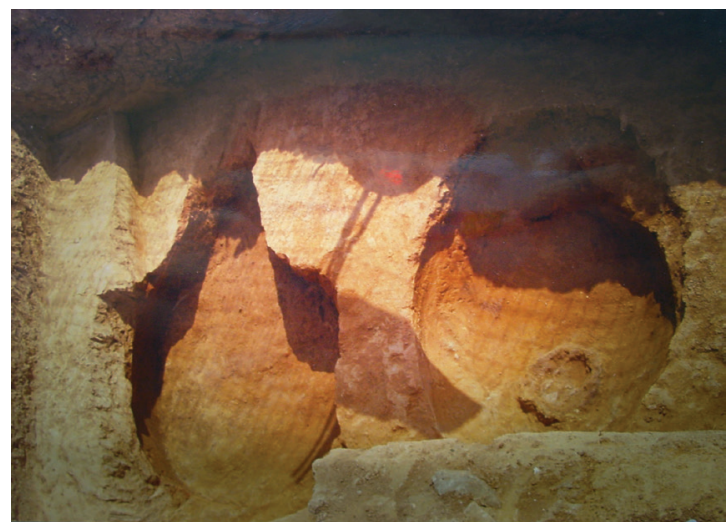

Fig. 8. Alquería de Safra: los dos hornos se encontraban a la misma altura y mantenían una tipología similar: cámara de fuego ovalada que sostenía una parrilla circular de poco más de un metro.

revestimiento cubriente de arcilla y una coloración blanquecina a causa de la acción directa del fuego. La estructura de la solería estaba compuesta por restos de adobes unidos con arcilla. El suelo de la cámara de fuego era convexo, las paredes divergían desde el mismo fondo y no se encontraron vestigios en el suelo de la cámara de una posible sustentación de la parrilla a través de un arco central o de columna alguna.

El segundo de los hornos se hallaba en peor estado de conservación, pero a pesar de ello se pudo constatar que tenía una tipología semejante al primero (Figs. 7 y 8). La cámara de combustión era de planta ligeramente oval y medía aproximadamente un metro y medio de diámetro y medio metro de profundidad, con una longitud total de 2,15 m, de los que $46 \mathrm{~cm}$ correspondían a la boca de la caldera. Solo se conservaba una parte de la solería horadada en el extremo oeste de la cámara. El horno presentaba la misma orientación que el primero, es decir, oeste-este, y también con la boca orientada hacia el camino. Dicha boca del hogar del horno se conservaba solo parcialmente, y estaba realizada con tierra endurecida que se quemó por la acción directa del fuego. En este caso sí que quedaban vestigios en el suelo de la cámara de fuego del arranque de la columna central, en forma de cilindro de arcilla, que sostenía la solería. La cámara de fuego tenía un suelo convexo y las paredes, 
como en el primer ejemplar, también se iban abriendo desde el mismo fondo.

En torno a los hornos se levantarían las dependencias que se destinarían al taller donde se realizaban las piezas, la provisión de la arcilla y la madera, al acopio de barro, al secado antes de su cochura, siempre a la sombra para evitar que se resquebrajaran las piezas, o a la custodia de las ya acabadas. Con todo, la excavación arqueológica únicamente permitió documentar un agujero de poste y una zanja excavada en el terreno, que bien podrían haber formado parte de un espacio auxiliar asociado a los hornos pero sin llegar a constituir infraestructuras estables. También se encontró una fosa que apareció colmatada con carbones, cenizas y desechos del establecimiento, junto a fragmentos cerámicos algunos de ellos decorados con cuerda seca parcial o turquesa.

Cuando los hornos fueron abandonados, se procedió a rellenar y nivelar el terreno que ocupaban con un estrato donde aparecieron las primeras cerámicas cristianas de los siglos XIII y XIV, fragmentos de platos con decoración pintada en verde y manganeso, loza azul, fragmentos de cuencos y platos con vidrio monocromo blanco, etc. Estos son los últimos indicios de una posible ocupación humana del lugar.

El interés de este yacimiento estriba en la localización de un obrador inédito en otra parcela, esta vez junto al margen derecho del Camí dels Molins, a escasos $500 \mathrm{~m}$ de los hornos que se habían documentado en la campaña del año 2001, por lo que sin duda podemos hablar de la existencia de varios talleres. Los nuevos hornos aparecieron dispuestos sobre una extensión suficientemente amplia, quizá se ordenaron en torno a un patio en el que también se situaría la balsa destinada a la preparación del barro. Alrededor se levantarían modestas construcciones destinadas al almacenamiento de la arcilla y la leña, al taller donde se realizaban las piezas con la ayuda de los tornos o el depósito en el que se guardaba el barro, al secado y barnizado de las vajillas antes de su cocción o a la conservación de las

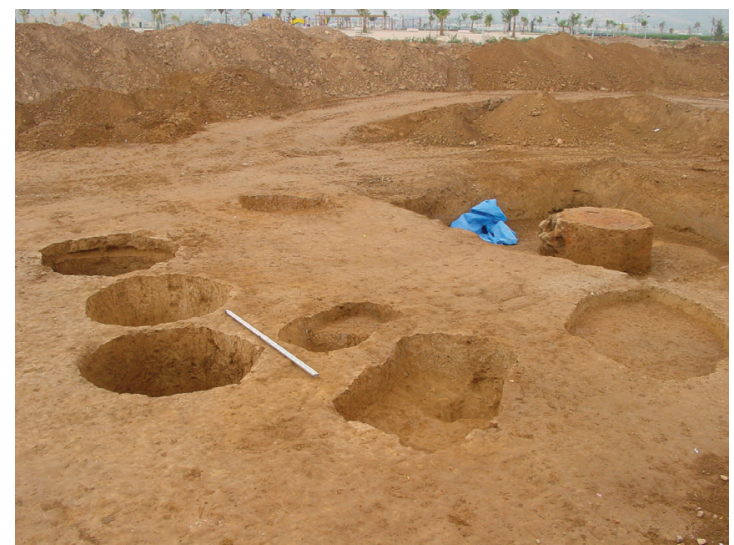

Fig. 9. Alquería de Safra: fosas de morfología circulary restos de estructuras excavadas en el terreno virgen, que aparecieron colmatadas con los desechos del horno que se localiza a la derecha de la fotografía.

ya acabadas. Así mismo, la notable cantidad de cerámica documentada junto a los hornos y contextualmente asociada a ellos, otorga un notable interés al estudio de las estructuras. Junto a los hornos se encontraron cinco fosas de morfología circular que aparecieron rellenadas con abundantes desechos de este establecimiento y numerosos fragmentos de cerámica, acompañadas de los restos de otras estructuras que originalmente bien pudieron formar parte de las balsas alfareras (Fig. 9).

Este nuevo horno tiene una orientación noreste-suroeste con la boca hacia el suroeste. Su parrilla presenta una planta circular de poco más de 1,20 m de diámetro. La longitud es de unos $2 \mathrm{~m}$, de los que $38 \mathrm{~cm}$ corresponden a la boca del hogar. Conserva casi la totalidad de la solería horadada o parrilla que ocupa todo el hueco de la cámara de fuego. Se conservan 8 perforaciones ligeramente ovaladas que tienen un diámetro que se mueve entre los 10 y $18 \mathrm{~cm}$ de la solera, la cual presenta, como en los ejemplos anteriores, un revestimiento cubriente de arcilla y coloración blanquecina. La estructura de la solería podría estar compuesta por restos de adobes unidos con arcilla, sin embargo, los adobes no parecen diferenciarse (Fig. 10).

La cámara de combustión es circular, mide 1,25 m de diámetro y 0,77 m de profundidad. No hay vestigios en el suelo de la cámara de 


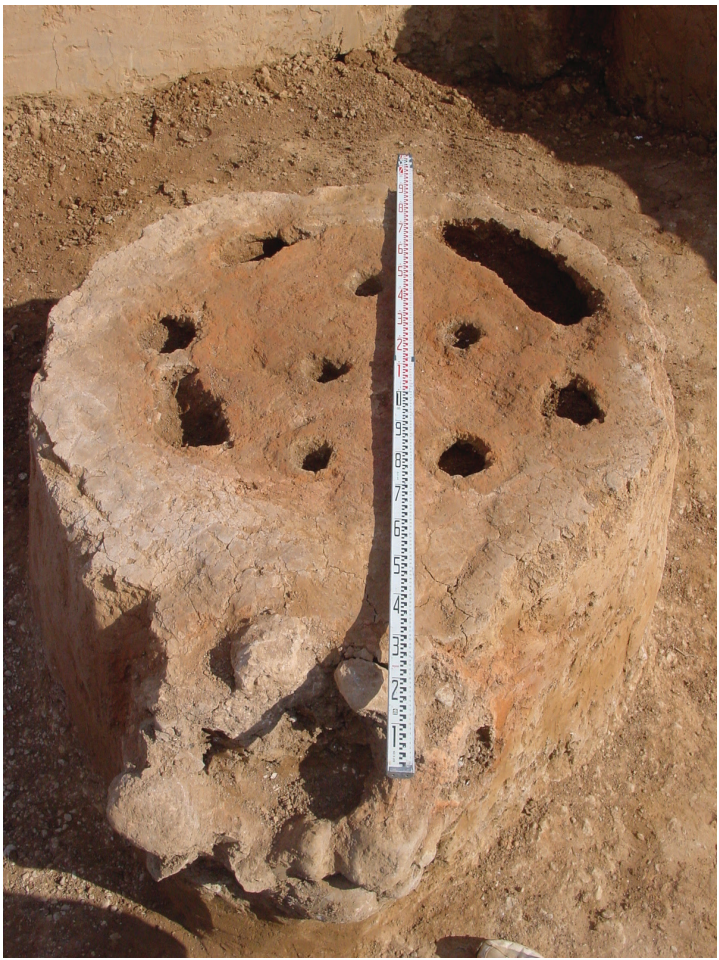

Fig. 10. Alquería de Safra: estructura del tercero de los hornos. Conserva parcialmente la boca del hogar, la caldera y la parrilla horadada.

fuego de sustentación de la parrilla a través de arco o columna de soporte central. La cámara de fuego, como en los anteriores, tenía un perfil convexo. Esta cámara presentaba un nivel de relleno formado por diferentes deposiciones que variaba desde una primera capa de tierra de textura arenosa y coloración marrón a un depósito de cenizas y carbones (Figs. 11 y 12). La base de la cámara de fuego se hallaba endurecida.

El cuarto de los hornos es el de tamaño más reducido y, sin embargo, el mejor preservado de todos ellos. Debido a su buen estado de conservación fue seleccionado para, después de una consolidación preventiva, ser trasladado al Museo de Bellas Artes de Castellón, donde permanece hoy en día en exposición en una de sus vitrinas (Figs. 13 a 15). El tamaño de este horno nos proporciona un volumen de cabida de apenas $1 \mathrm{~m}^{3} \mathrm{y}$, por tanto, estimamos que en las hornadas entraría una media de unas 15 docenas de piezas.

El horno tiene una orientación noreste-suroeste, con la boca hacia el suroeste. Consta

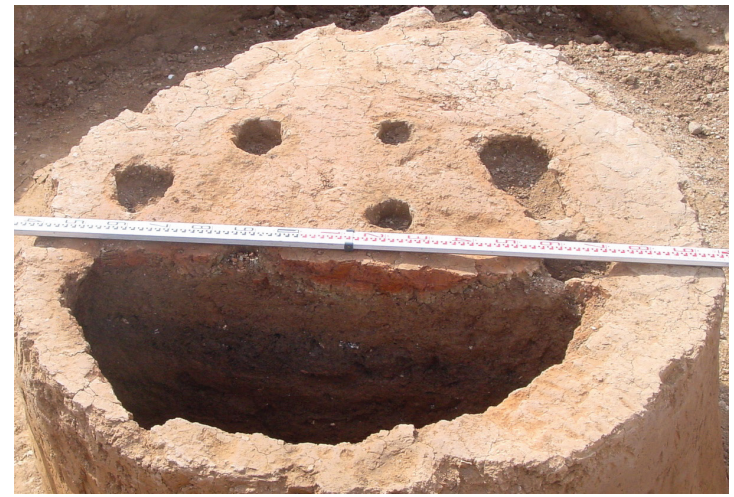

Fig. 11. Alquería de Safra: en el interior de la cámara de fuego se puede observar cómo están dispuestos los diferentes depósitos de cenizas, arcillas y cascotes de arcillas.

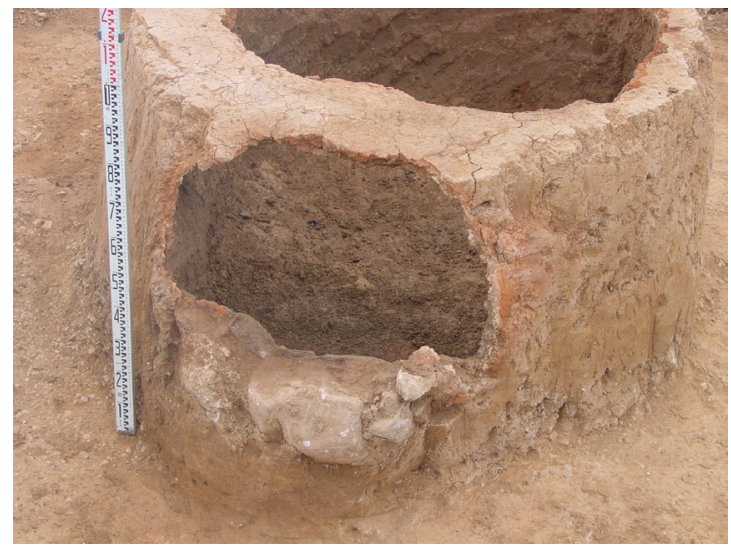

Fig. 12. Alquería de Safra: la boca del hogar del horno sólo se conservaba parcialmente y estaba realizada con tierra endurecida que se quemó por la acción directa del fuego.

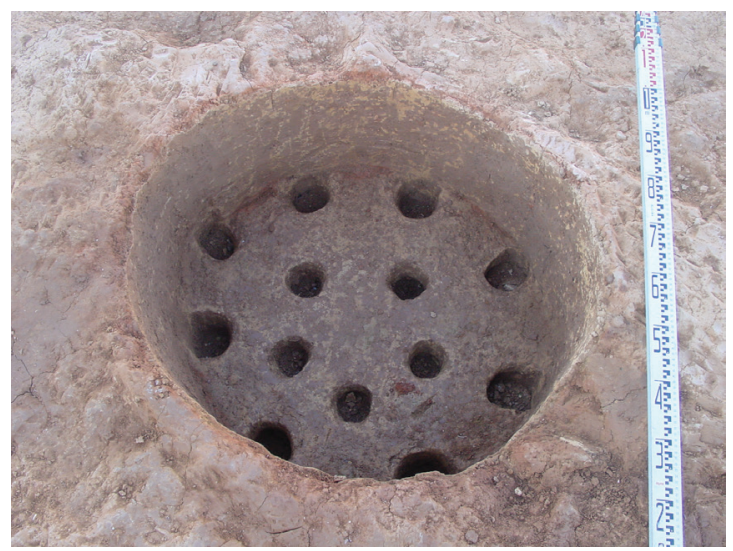

Fig. 13. Alquería de Safra: el horno conservaba, cuando se descubrió, la totalidad de la solería horadada, con trece conductos de $10 \mathrm{~cm}$ de diámetro cada abertura.

de una parrilla circular de únicamente $87 \mathrm{~cm}$ de diámetro. La longitud de toda la estructura 

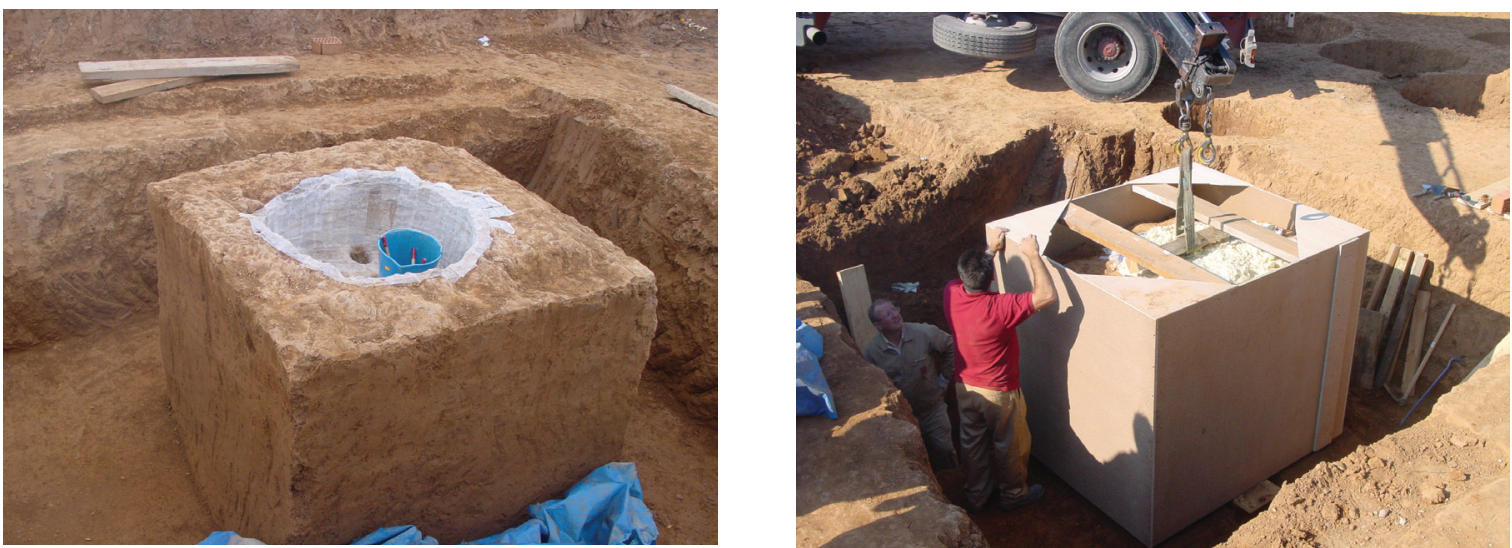

Fig. 14 y 15. Alquería de Safra: los trabajos prepararon el terreno para la posterior extracción del horno y traslado definitivo al Museo de Bellas Artes de Castellón.

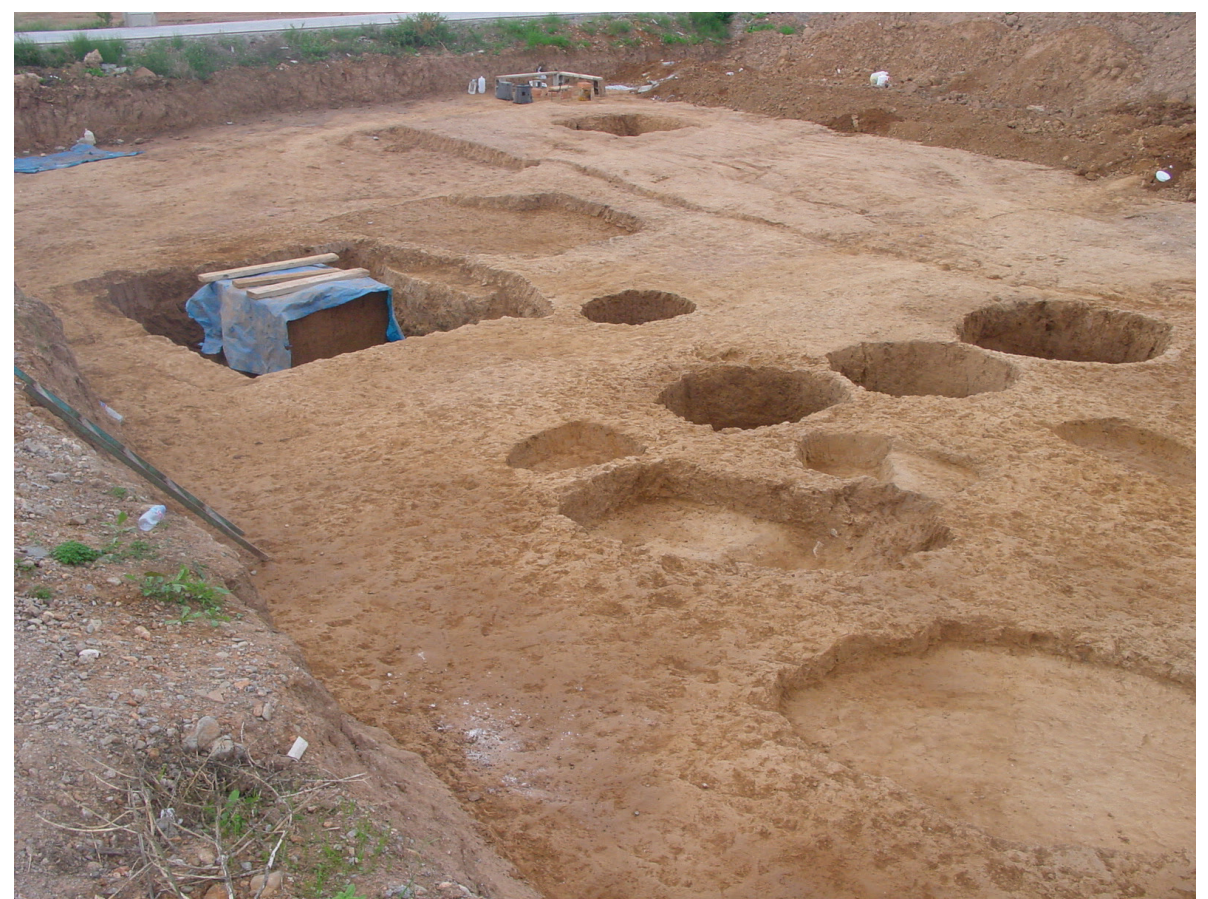

Fig. 16. Alquería de Safra: parcela donde se excavaron los restos de uno de los hornos y del espacio donde se pudo tratar la arcilla.

de cocción es aproximadamente de 1,30 m, de los que $46 \mathrm{~cm}$ corresponden a la boca de la cámara de combustión. También mantiene parte de la base de las paredes del laboratorio que se levantan directamente sobre la parrilla. La boca del hogar del horno está íntegra, se realizó con tierra endurecida que encontramos quemada por la acción del fuego. La fosa se revistió con barro rojizo.

En este sector del taller, no conocemos exactamente cómo era el espacio que sirvió para tratar la arcilla en bruto, decantarla y prepararla, y tampoco dónde conservaban el combustible. No se han hallado los restos de las balsas para la levigación, ni se han detectado estructuras que pudiéramos interpretar como zonas de amasado de la arcilla por pisado. Pero junto a la estructura de los dos hornos se documentó un conjunto de fosas y silos excavados en el terreno aluvial, que pudieron desempeñar alguna o parte de estas funciones y que durante los trabajos de excavación se encontraron colmatados por los desechos de los propios hornos (Fig. 16). Sus medidas variaban de los dos a tres metros y 
aproximadamente entre 1 metro y $20 \mathrm{~cm}$ de profundidad.

El torneado de las piezas tendría un esquema semejante a los que todavía pueden verse en algunas alfarerías de Andalucía. Al parecer, se practicaría en otra estancia aunque su ubicación no parece entreverse por los hallazgos de la excavación. Es probable que estos tornos pudieran ser de árbol fijo y rueda volante, o tal vez se utilizaran ya tornos elevados con estructura de madera, circunstancia que explicaría el hecho de que no se hayan encontrado. El torno de árbol fijo, con banco de madera, propulsado mediante una rueda con radios impulsada con un bastón o quizás un operario, representa el modelo más arcaico de torno rápido, y podría indicar también unos menores recursos económicos de los alfareros y su especialización en un producto de menor valor, alfarería de basto, no de mesa, esencialmente bizcochada. Este modelo debió permanecer durante mucho tiempo en los talleres de producción de alfarería bizcochada en todo el mundo árabe.

Por otra parte, el secado es una fase del proceso de producción bastante difícil y delicada, pues influye de forma notable la naturaleza y la calidad de las pastas. Las arcillas más plásticas requerirán más lentitud y sutileza en el proceso, mientras las refractarias o con desengrasantes serán más resistentes y permitirán la reducción de tiempo mediante su exposición directa al sol. Las piezas simples y sin asas, o de grosores uniformes, también serían más resistentes, mientras las que tenían aplicaciones o asas requerirían más cuidado y por tanto más tiempo. En otros yacimientos se ha sugerido que el secado se realizaría en salas cubiertas donde también se encontrarían los hornos y que se pudieron usar además como almacén de cerámica (COLL, 2009).

\section{¿EL ALFAR DE LLEDÓ?}

La basílica de Nuestra Señora del Lledó está localizada en la partida de la Plana junto al Caminàs, antigua vía litoral de origen prerromano que discurre al este del núcleo urbano de Castellón, una zona muy rica en hallazgos arqueológicos de época musulmana y romana. En el margen izquierdo del camino, durante los años 2005 y 2006, fue hallada la maqbara con 42 sepulturas individuales sin ajuar (BENEDITO, MELCHOR, 2018).

El lugar de los hallazgos es la parte adjunta de la fachada principal del templo (Fig. 17). En 1982, con motivo de las obras de pavimentación de la explanada, el Servicio de Arqueología de la Diputación castellonense llevó a cabo una excavación arqueológica en una reducida zona en la que aparecieron los restos de un silo de época andalusí excavado en la arcilla, que alcanzó una profundidad de 2,90 m, y lo que podría ser la cámara de combustión de un horno (GUSI, 1985; GUSI et alii, 2000) (Figs. 18 y 19). Sin embargo, la publicación no ofrece más detalles constructivos por lo que deja lugar a ciertas dudas respecto a la correcta interpretación de este hallazgo como un horno cerámico.

\section{LA PRODUCCIÓN CERÁMICA}

La totalidad de las piezas cerámicas que se recuperaron durante la excavación de los hornos del Camí dels Molins obedecen a la misma técnica de fabricación de cerámica sin vidriar. Sabemos qué tipo de loza se cocía gracias al hallazgo de un conjunto de ollas que pertenecían a la misma hornada y que rellenaban la caldera de uno de los hornos. La parrilla se había hundido por el peso de la carga y las ollas se desplomaron al interior de la cámara (Fig. 20).

Pero estos hornos estaban preparados para cocer diversas producciones: cerámica de uso alimentario, de almacenamiento, servicios de mesa, bacines, contenedores de agua, fogones portátiles, cerámica bizcochada o piezas con óxidos vitrificantes (Fig. 27); y de diversos formatos, pero en este caso concreto fueron destinados a preparar con fuego reductor cerámica culinaria, como lo demuestran las ollas localizadas en el interior. Su cocción se 

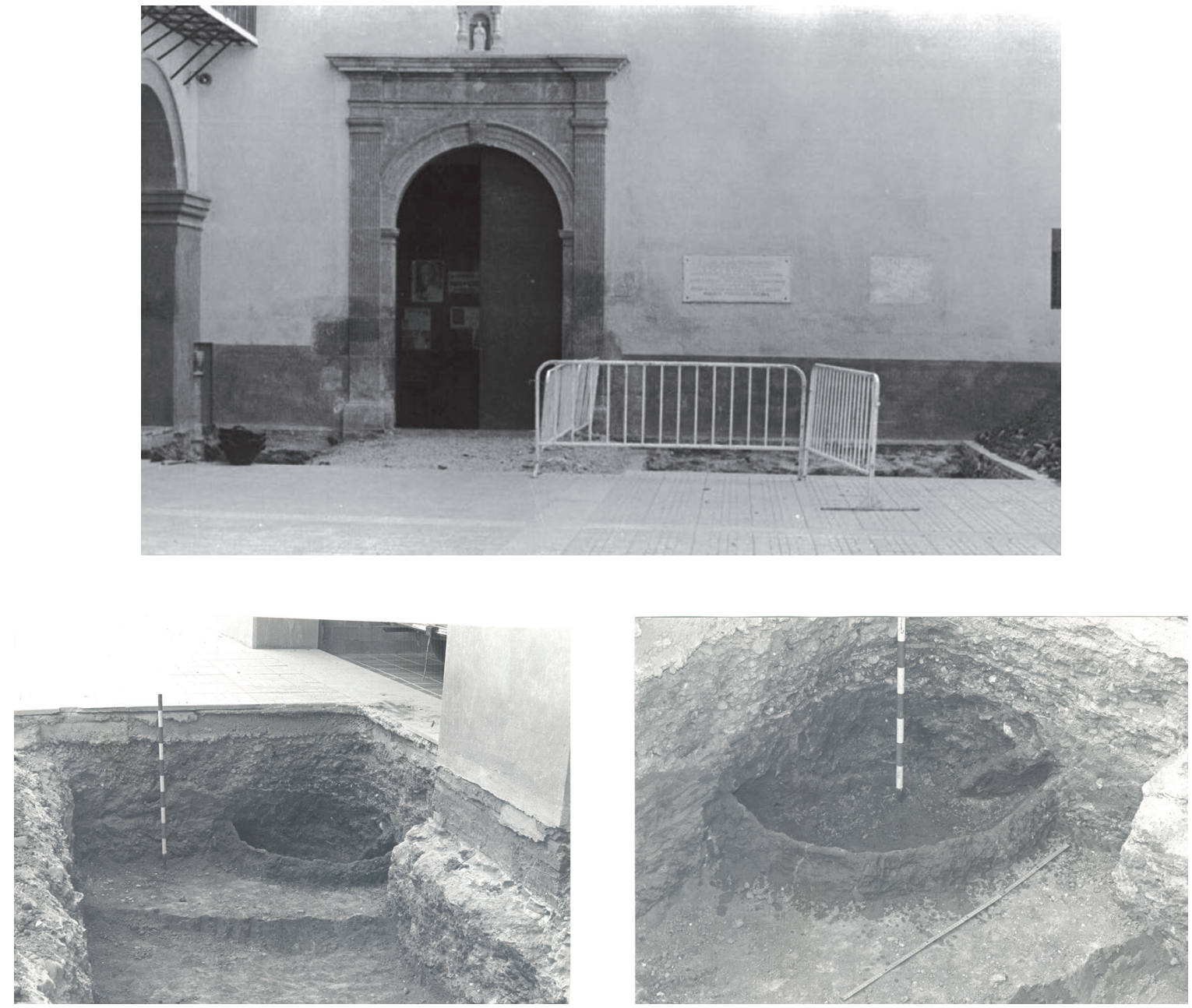

Figs. 17 a 19. Lledó: sondeos arqueológicos que se realizaron en la fachada de la basílica en 1982 y detalle de la excavación de la cámara de combustión de un posible horno de época musulmana (Foto: SIAP).

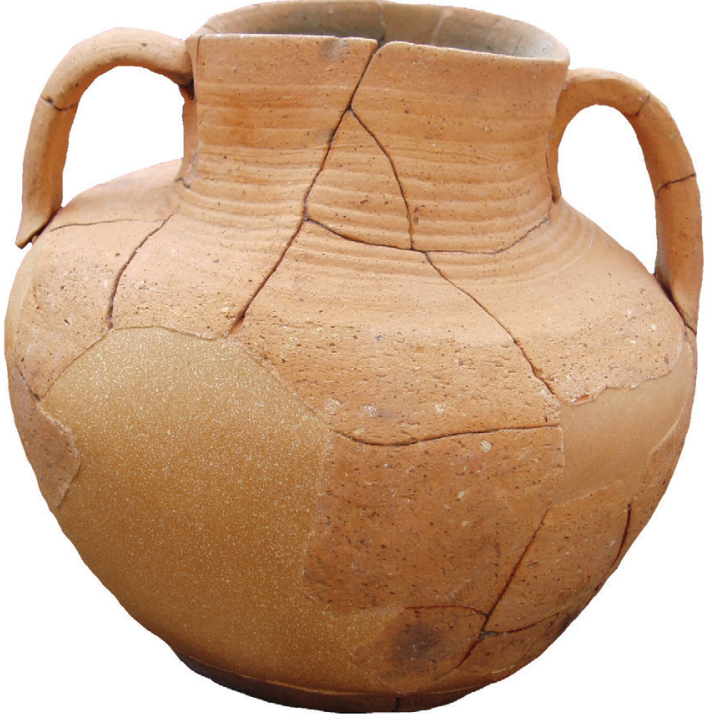

Fig. 20. Alquería de Safra: olla deformada durante la cocción. hizo llenando de humo la cámara correspondiente al laboratorio para que dichas piezas adquirieran una coloración grisácea ahumada más o menos uniforme.

En el interior del horno descubierto junto a la ermita de Sant Jaume de Fadrell, se encontraron muchos restos de ataifores o platos en general, pero no de ollas. Por lo que las ollas halladas en la excavación podrían pertenecer a otros hornos que no llegaron a excavarse y que, como se ha mencionado, tal vez se hubieran construido en las proximidades.

Entre el utillaje alfarero no se han encontrado los moldes, por lo general de barro cocido, que generalmente eran utilizados para el estampillado de grandes superficies 
diseñando metopas, bandas y grandes cartelas epigráficas, fitomorfas o zoomorfas. Para la cocción se usaron los trébedes como separadores de las piezas barnizadas que se cocían para evitar que se pegasen, usados con profusión hasta hoy en día.

Toda la cerámica se caracteriza por una alta porosidad y ligereza, y las grandes vacuolas y partículas calcáreas son perfectamente visibles en su superficie. Las pastas de la cerámica suelen presentar abundantes desengrasantes refractarios de cuarzo (arena de río). Entre las técnicas de acabado de las superficies, se utilizaron los sistemas más simples, que no ofrecen prácticamente decoración y solo alisados o bruñidos.

\section{CERÁMICAS CALIFALES Y DE LOS REI- NOS DE TAIFAS}

La cerámica que hoy en día provoca más desconcierto es la de los reinos taifas, tanto es así que ignoramos cómo eran realmente las piezas realizadas en los alfares de Castellón durante estos periodos. Sabemos que en el siglo X probablemente se hicieron algunas marmitas, los primeros jarritos, cántaros, ollas y lebrillos, todos ellos desprovistos de vedríos, pues se han encontrado algunos ejemplares de estas características en las excavaciones (Fig. 21).

Poco después se dio paso a las innovaciones que revolucionaron los hornos de todo el territorio andalusí, básicamente por la introducción del vidriado, la gran novedad técnica del momento, que podemos encontrar en muchas de las piezas catalogadas en las excavaciones de los alfares localizados en Castellón. Una de las primeras piezas pintadas en estas alfarerías se hizo de forma sencilla y con un solo color, generalmente con manchones en negruzco de óxido de manganeso o de hierro. Poco a poco se van generalizando los revestimientos vidriados de plomo verde o melado, apareciendo de forma muy tímida las decoraciones estanníferas. En las cerámicas, tras la primera cochura, cuando la pieza estaba en juaguete,

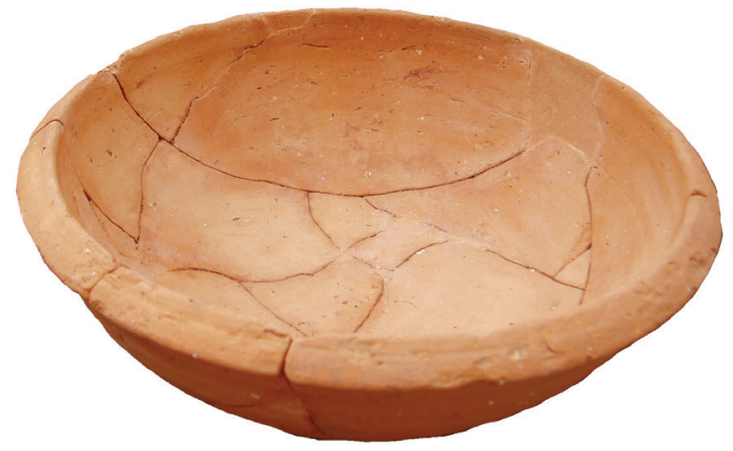

Fig. 21. Alquería de Safra: plato hondo cóncavo modelado a mano.

se aplicaba el óxido metálico vitrificante elegido. Y después de una segunda cocción, la pieza resultaba brillante gracias a la cubierta vítrea. En la segunda mitad del siglo X se utilizó con profusión el vidriado, en cuencos y platos melados, cantarillas y jarras. También debieron fabricarse redomas, fuentes y cantarillas decoradas en óxido de manganeso sobre melado o simplemente con cubierta melada de plomo, pues se han encontrado varios ejemplos de este tipo en las excavaciones. Otras lozas, más interesantes, llevan ya decoración en manganeso sobre melado, y verde y negro sobre blanco que apunta a una fecha del siglo XI.

Otra técnica de mucha calidad que se fabricó especialmente a inicios del siglo XI aunque de vida más prolongada, es la cuerda seca, nombre que se ha propuesto a un tipo de decoración en manganeso mezclado con una sustancia grasa y óxidos colorantes vitrificados en una segunda cocción. Es una técnica decorativa típicamente hispanomusulmana, que combina vidriados de diversos colores yuxtapuestos y separados por una línea muy fina de cerámica bizcochada que aparece unas veces sin vedrío y otras con pintura de manganeso. Puede presentarse cubriendo totalmente la superficie del vaso, es decir la cuerda seca total, en cuyo caso el resultado es semejante a la técnica de esmaltado del cloissonné, que se aplica a la decoración de objetos de metalistería. Pero cuando el vidriado se reduce a elementos sueltos en una parte de la pieza, se denomina cuerda seca parcial. La cuerda seca total es generalmente más rica en color y puede combinar esmalte estannífero con 
vedríos pigmentados con manganeso, hierro, cobre, o esmaltes turquesa de cobre y estaño. La cuerda seca parcial se presenta en ocasiones con zonas pintadas y otras esgrafiadas. Un plato excepcional, policromo, de cuerda seca, con representación zoomorfa procede de Fadrell, así como otros con motivos florales cuya característica es cubrir siempre toda la superficie interior de la pieza. Pero esta pieza no fue fabricada en estos alfares sino que procede del comercio con el territorio de al-Andalus.

Cabe destacar que la mayor parte de la loza de cocina de este momento que se ha encontrado en las excavaciones no lleva recubrimiento de barniz de plomo, quizá en general éste es todavía un elemento algo costoso, de forma que las cazuelas, ollas, cántaros y lebrillos se siguen realizando en bizcochado. La excavación del alfar de Fadrell proporcionó ollas bizcochadas de cuerpo globular y cuello cilíndrico ligeramente divergente, con acanaladuras que a veces se extienden sobre la parte superior del cuerpo y que se han fechado entre los siglos X y XI. También apareció una olla pequeña con restos de vidriado melado que podría ser posterior (COLLADO, NIETO, 2008). Armengol hace una mención especial de un jarrito bizcochado con cuerpo globular de reducidas dimensiones y cuello troncocónico muy desarrollado, con acanaladuras (ARMENGOL, 2013), que P. Guichard comparaba con los hallazgos de la ciudad de Burriana de los siglos IX al XI. Más adelante este barniz acabará por generalizarse en las piezas cerámicas.

\section{CERÁMICAS DEL PERIODO DE LOS IMPERIOS AFRICANOS (ALMORÁVIDE Y ALMOHADE)}

Parte de la producción de los siglos XI y XII la encontramos entre los desechos de los alfares excavados en Castellón. En loza estannífera se han identificado botellas o redomas, éstas en vidriado de color verde claro, cantarillas bizcochadas con pintura de trazos finos realizados en manganeso o sin decoración, jarros con trazos de manganeso

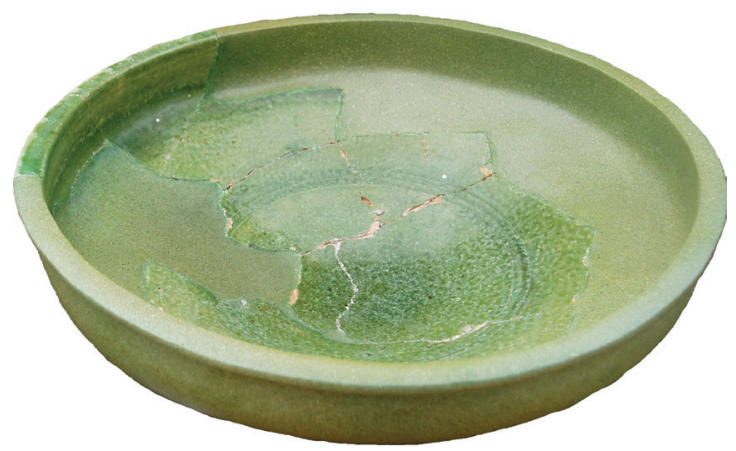

Fig. 22. Alquería de Safra: ataifor de perfil semiesférico con repie anular en la base. Está cubierto con barniz de plomo de color verde monocromo.

y algunas cazuelas realizadas a mano. El alfar de Fadrell, en los niveles de ocupación del siglo XII, amplía el repertorio ofreciéndonos marmitas, cántaros, tapaderas y ataifores de perfiles carenados (Fig. 22). En este caso algunas de las piezas fueron realizadas con la técnica del bizcocho, otras con barniz de plomo en verde monocromo, o en manganeso sobre melado, además de aparecer la cuerda seca parcial y el esmalte estannífero y cobre de color turquesa.

Respecto a las otras cerámicas vigentes en ese momento, junto al Camí dels Molins encontramos ollas de cocción reductora de cuello acanalado y exvasado, así como otras de pasta clara y paredes más finas, cazuelas de exterior acanalado, cantarillas bizcochadas de pasta clara de cuello cilíndrico y decoración pintada, fuentes o cuencos de perfiles semiesféricos y con repie anular decoradas en verde y negro sobre estannífero. También se percibe un incremento de las fuentes y platos de vidriado monocromo estannífero con perfiles carenados. Las redomas se cubren con esmalte de estaño simple, y muy escasamente con vidriados de plomo con trazos de manganeso. El repertorio se completa con cántaros, tapaderas, tinajas y lebrillos.

La cerámica de la fase almohade presenta un repertorio formal y decorativo mucho más rico que en las etapas anteriores, desapareciendo vajilla previamente arraigada y apareciendo otras formas nuevas. Al uso doméstico 
se incorporan piezas refinadas, como pueden ser las jarritas en las que aumenta la calidad decorativa, incorporando la cuerda seca, esgrafiado, a veces esgrafiado combinado con cuerda seca, y las tinajas con decoración de temática epigráfica, donde suelen repetirse las palabras baraka (bendición), al-mulk (el Poder es de dios), al-kalima (la palabra), al-Tawfiq (la asistencia divina, el éxito que da dios, la ayuda, la suerte) o al yumn (la prosperidad). Es importante hacer hincapié en la frecuencia de la aplicación de la estampilla epigráfica sobre el recipiente, pues la eulogia ejercería un valor profiláctico sobre el contenido. En la estampilla de la tinaja que salió a la luz en las excavaciones aparece la expresión al-mulk², que recuerda al buen creyente la omnipotencia divina (Fig. 23). Por otra parte, la cerámica alcanza un mayor nivel técnico por la generalización de las cubiertas de plomo en todo tipo de piezas y en especial en cerámica de fuego. Pero sin embargo estas cerámicas apenas aparecen representadas en Castellón.

Es interesante recurrir nuevamente al repertorio documentado en los centros de producción de Safra y Fadrell. En estos lugares se hallaron zafas con vidriado verde de plomo y cobre, fuentes en verde y manganeso sobre blanco, cuencos con vidriado verde intenso y decoración estampillada, redomas en verde, cantarillas bizcochadas con pintura en manganeso, ollas o jarros bizcochados, cazuelas barnizadas, escudillas con barniz de plomo, lebrillos con cordones incisos, ollas globulares bizcochadas, arcaduces, tazas de cuerda seca parcial, etc. El esgrafiado se encuentra tímidamente en escasos fragmentos, indicando tal vez su importación. Las fuentes, cuencos y escudillas presentan ahora perfil carenado, y sus decoraciones se limitan a trazos curvos sobre piezas barnizadas o esmaltadas algunas en turquesa. En cerámica común existen nuevas formas, como los cántaros de cuello largo con borde alto y engrosado decorados en óxido de hierro o manganeso, mientras las

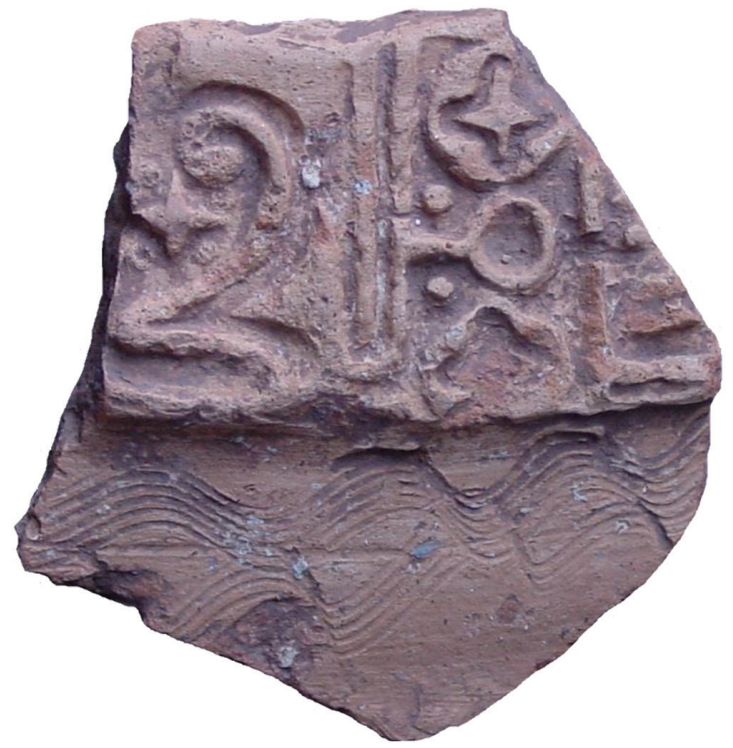

Fig. 23. Alquería de Safra: fragmento de tinaja decorada con estampillas. La pasta está poco decantada y predominan los desgrasantes gruesos. Los motivos representados son epigráficos donde se lee la eulogia al-mulk a partir de las letras alik, nexo mîm, lam y la kâf. Completa la decoración estrellas aisladas y motivos vegetales.

tinajas de cordones digitados aplicados ofrecen motivos más complejos.

La cerámica de Sant Jaume de Fadrell ha sido estudiada por P. Armengol (ARMENGOL, 2013). Respecto a la bizcochada, se han detectado formas cerradas, tanto reductoras como oxidantes, mayoritariamente ollas o cántaros y también jarritos y jarritas. Algunos bordes de las ollas presentan acanaladuras, mientras que otros bordes de jarritas son lisos. Se han encontrado también diversos fragmentos de ollas con acanaladuras en el cuello y borde engrosado en el exterior, de sección triangular y un borde de cazuela con perfil en " $S$ " y acanaladuras. Hay también algunos bordes más toscos que podrían formar parte de fogones, una posible base de alfabia y un borde de brasero, que suele aparecer habitualmente en contextos de los siglos XI y XII. En cuanto a los vidriados, hay que decir que prácticamente todos los fragmentos corresponden a formas abiertas, que pese al deterioro que presentan, parece

2. Nuestro agradecimiento a la profesora Ana Labarta, por la colaboración prestada en la lectura de la estampilla. 

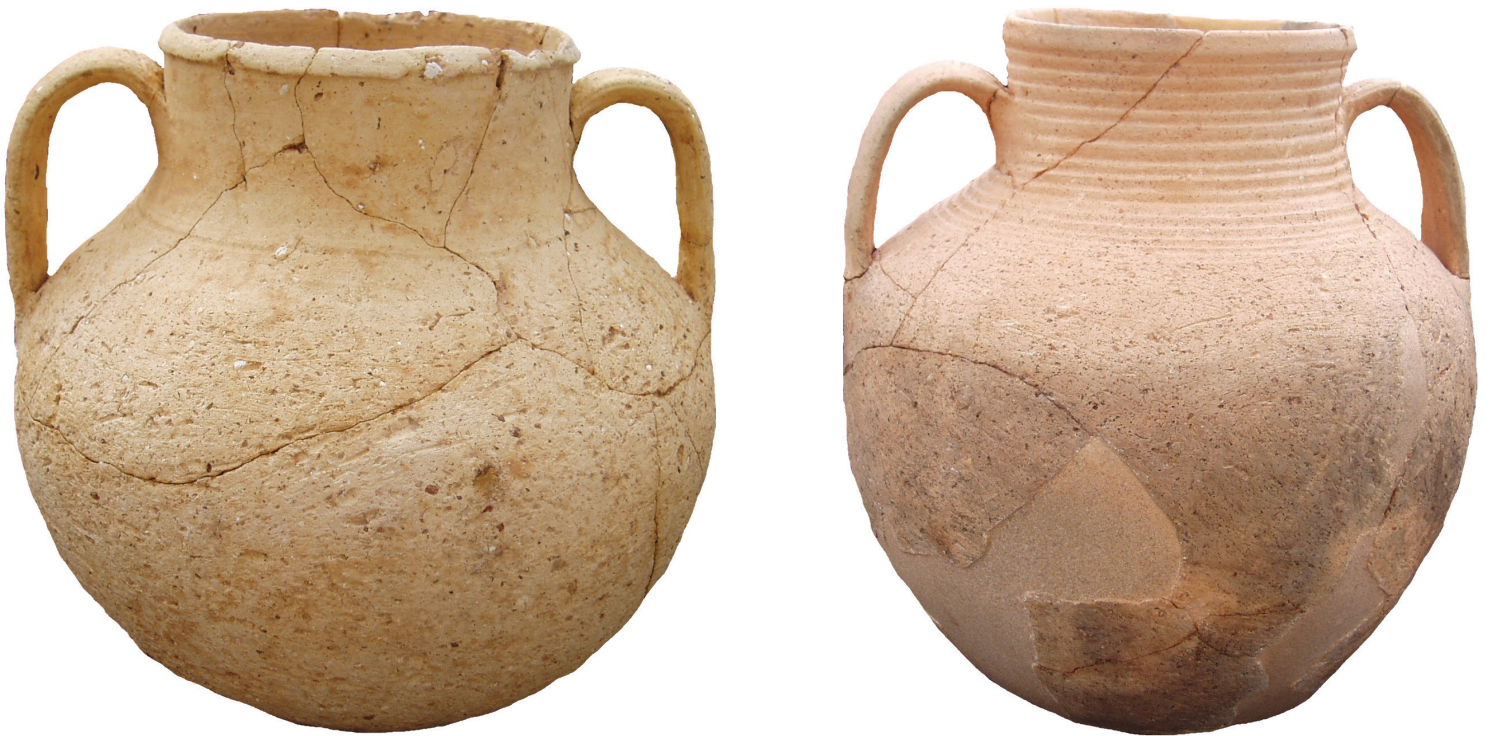

Figs. 24 y 25. Alquería de Safra: ollas de cuerpo globular y boca ancha, sin vidriar. En un recipiente la superficie es lisa mientras que la otra olla tiene el cuello acanalado.

que serían blancos en el anverso. Hay también fragmentos melados y vidriados monocromos de color verde oscuro, de época almohade.

Las escasas bases que han aparecido son anulares y probablemente han llevado un vidriado blanco en el anverso. Se han encontrado también algunos fragmentos de bordes de zafas: una misma pieza conformada por dos fragmentos con borde y labio divergente, una hemisférica con labio engrosado, otra hemisférica sin ningún tipo de engrosamiento del labio y una cuarta con un labio plano engrosado, que probablemente pertenecen a un momento anterior al periodo almohade. Hay algunos fragmentos con decoración bicroma en marrón sobre melado, y por último, un borde de forma cerrada con vidriado monocromo melado.

La producción del taller del Camí dels Molins incluye un numeroso lote de fragmentos cerámicos donde la serie más representada es la cerámica de cocina y la común, decorada alguna de ellas con óxido de hierro y óxido de manganeso. En cuanto a la tipología, las formas fundamentalmente se repiten, siendo las ollas y ollitas las más abundantes seguidas por las jarras (Figs. 24 y 25). Dentro de las ollas/ ollitas hemos encontrado una gran variedad tipológica que ha permitido realizar una clasificación por sus similitudes morfológicas. Por ello diferenciamos en dos subtipos la forma más representada en las excavaciones, integrando en el primer subgrupo una forma con borde recto entrante con labio convexo y dos asas de cintas verticales. El segundo subtipo presenta una base ligeramente convexa con cuerpo globular y borde saliente, moldurado o apuntado, con acanaladuras en el cuello (CLARAMONTE, BENEDITO, MELCHOR, 2008).

Siguiendo con la serie de cocina, la cazuela, contenedor que se aplica al fuego para guisos con poco líquido, se ha registrado un solo fragmento que corresponde a una forma de borde entrante con labio convexo simple y asas. Presenta cubierta vítrea de tonalidad verde.

De la forma abierta de alcadafe o lebrillo, destaca el tipo caracterizado por una base plana, cuerpo troncocónico invertido y borde saliente. La decoración que se ha podido documentar en este lote presenta motivos a peine e incisos.

En cuanto al grupo de cerámica común podemos hablar de los elementos pertenecientes al servicio de mesa como es el jarro que corresponde a una forma con borde recto 
o trilobulado y cuello bajo simple estrecho, y que no presenta ninguna cubierta vítrea (Fig. 26). De los cántaros destaca el tipo caracterizado por una base plana, cuerpo elipsoide vertical con dos asas, cuello estrecho y borde recto o moldurado. La decoración se resume en trazos pintados con óxido de hierro y óxido de manganeso sobre las acanaladuras.

El tipo representado en la excavación de ataifor, plato de servicio con una tipología sumamente variada, es la de base con repie anular, cuerpo semiesférico y borde saliente moldurado. Documentando tanto motivos pintados de color verde o manganeso como cubierta vítrea.

La forma de la jofaina, plato de reducido tamaño, se compone de fragmentos correspondientes al modelo de cuerpo en casquete hemisférico con borde saliente o recto y labio convexo y sin presencia de cubierta vítrea.

En el grupo de elementos de almacenaje destacaremos la presencia de la forma de jarra, contenedor de servicio de mediano tamaño y que responde a la forma de base plana con cuerpo elipsoide vertical, de cuello cilíndrico alto, con el borde recto o moldurado y labio convexo. Presenta asas de cinta verticales. La forma de tinaja o tinajilla, recipiente de grandes dimensiones, está muy poco representada. Los únicos ejemplos presentan borde saliente o borde moldurado. En algún caso aparecen con decoración incisa a peine, cordones plásticos con incisiones o digitaciones en el labio.

En lo referente a la decoración de las piezas, se ha podido diferenciar diferentes tratamientos o decoraciones: el grupo adscrito a la cerámica sin vidriar, se caracteriza por presentar la superficie bizcochada, es decir, sin aplicación de vedrío. En las cerámicas grises no se han documentado apenas variantes, se observa una similar preparación de las arcillas y en el tratamiento de los desgrasantes, tanto como en el proceso de cocción. La primera característica de las cerámicas grises documentadas es el neto predominio de las ollas sobre las restantes formas.

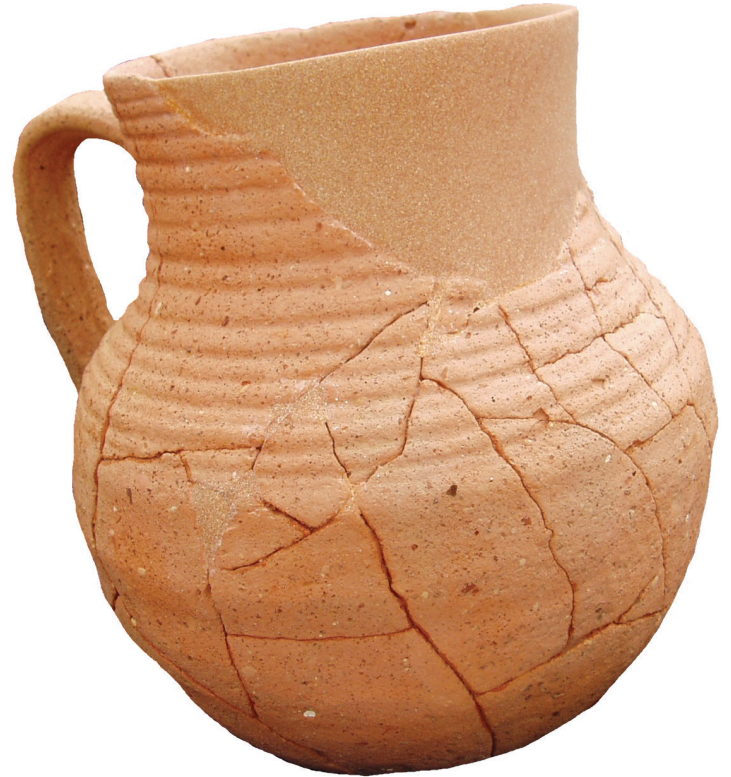

Fig. 26. Alquería de Safra: jarro hecho a torno de época califal, con un asa y el cuello decorado a base de acanaladuras.

En función de la decoración que conservan, distinguimos pigmentaciones, engobes, barnices y esmaltes. La más escasa es la decoración incisa. Realizada mediante la aplicación de motivos a peine o punzón, básicamente meandros o bandas, sobre la pieza cruda que tras el secado eran rayadas. El repertorio es simple y se reduce a la utilización de bandas horizontales y onduladas.

La decoración impresa y la decoración ungulada es una de las técnicas más sencillas, que afecta básicamente al modelado y aplicaciones ornamentales. En su mayoría, bordes con digitaciones/ungulaciones en la parte superior externa.

En ocasiones, la decoración se aplicaba con una barbotina muy líquida compuesta por la arcilla pigmentada o de otro color, a veces blanquecina. Con esta técnica se decoraban las cerámicas comunes (jarras, cántaros, lebrillos, ollas, etc.). Se han encontrado engobes de barbotina de color rojo que sirven de fondo a motivos pintados en colores contrastados como el blanco.

Las decoraciones pintadas se realizaban con pigmentos metálicos de óxido de hierro 

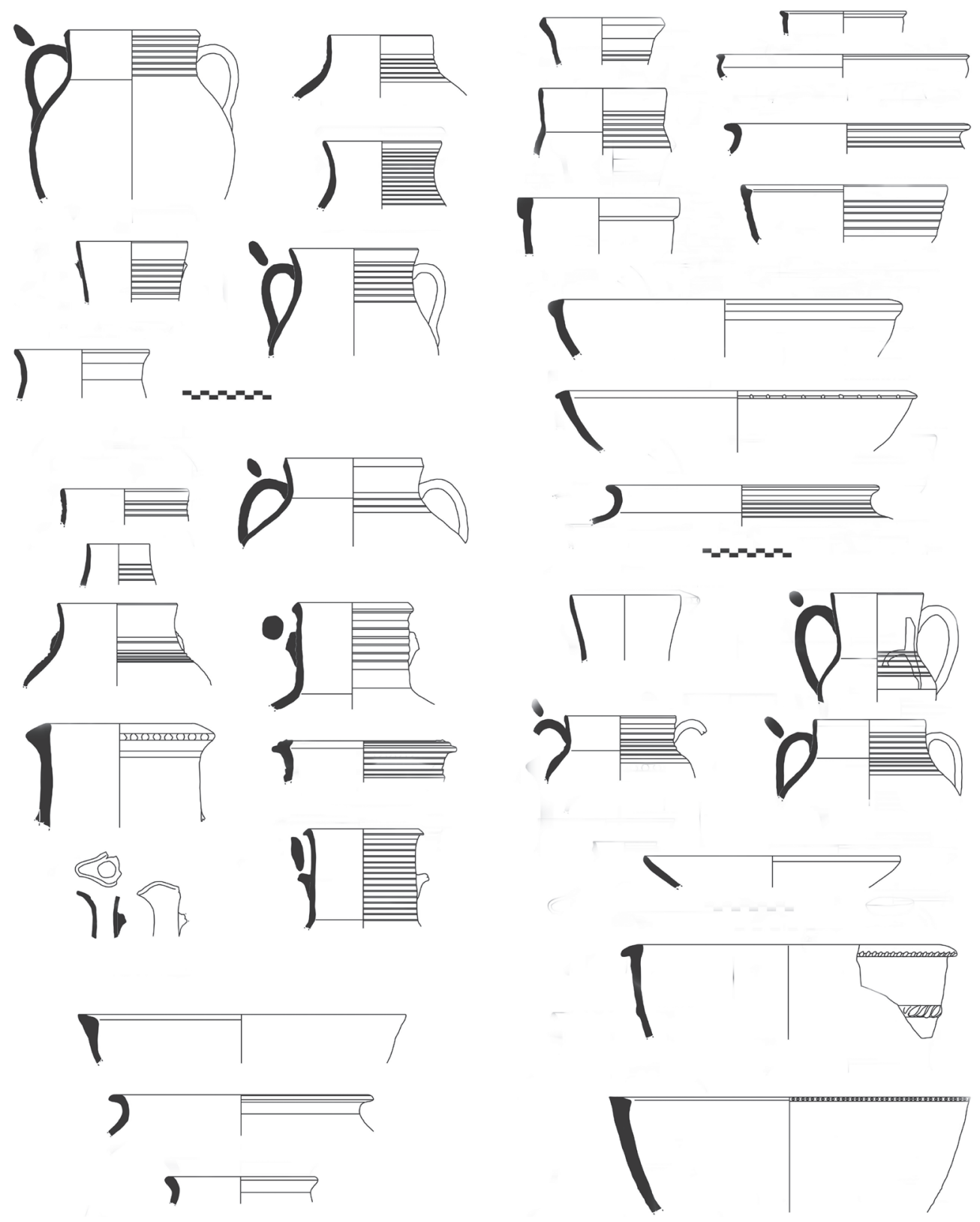

Fig. 27. Alquería de Safra: resumen de tipos cerámicos documentados en la excavación.

(rojo) o de manganeso (negro). Los motivos son sencillos. Las principales materias colorantes son óxidos metálicos. El óxido de hierro produce el color rojo en cocción oxidante y negro en reducción, tanto al ser usado en un engobe como en un barniz o cubierta. El cobre da verde en oxidación y rojo en reducción.

El lote de cerámica vidriada está representado por un grupo poco numeroso de piezas donde se diferencia la siguiente clasificación: vidriados monocromos que se da en tres variedades, cubierta vítrea de tonalidad melada, verde y cubierta vítrea de tonalidad amarillenta (en estos casos la calidad del vidriado es deficiente). En cuanto a las cubiertas vítreas usadas, encontramos dos grandes grupos según los fundentes mayoritarios utilizados. Un grupo presenta mayor cantidad de sales de sodio y potasio (cubiertas alcalinas), mientras otro grupo lo constituyen las cubiertas con plomo como fundente principal. En éstas, para formar el vidrio es esencial el plomo, sílice, y componentes básicos como 
el bórax o la sal. Algunos pigmentos varían de color en función de la mayor o menor proporción de fundentes alcalinos de la cubierta, así el cobre da el color turquesa cuando la proporción de esas sales en el barniz es alta. También se consigue un color verde turquesa pálido si se diluye el cobre en una cubierta de plomo-estaño. Las cubiertas traslúcidas se realizaban esencialmente con barniz de plomo, a partir de galena (sulfuro de plomo), litargirio o minio (óxido de plomo). Este producto, una vez enfriado, volvía a cocerse en la cámara baja del horno, junto con arena de sílice, formando un vidrio. Este vidrio se molía y refinaba, obteniéndose un polvo que se suspendía en agua y con ello se conseguía el barniz. Para conseguir cubiertas opacas simples (verdes, marrones, etc.), se añadían a la preparación de la cubierta de plomo óxidos metálicos colorantes, los verdes óxido de cobre, y óxido de manganeso los marrones. De ese modo, la adición de óxido de cobre disuelto en vinagre al preparado del barniz tinta al vidrio de un color verde hoja. $\mathrm{Si}$ al barniz de plomo le añadimos estaño obtendremos una cubierta blanca opaca. Estas cubiertas opacas estanníferas fueron la innovación técnica más trascendente de la herencia hispanomusulmana. Se componen de plomo, sílice, escasos fundentes alcalinos sódicos y potásicos, y óxido de estaño como opacificante. Para fabricar esmalte estannífero se mezclaba el vidriado de plomo con óxido de estaño, arena y otros fundentes (sodio o potasio).

Verde y manganeso. Esta decoración está representada por muy pocos fragmentos. Algunas producciones están decoradas en negro, o verde y negro sobre melado. Estas decoraciones se obtienen aplicando el pigmento sobre - bajo la cubierta de plomo. En general, las decoraciones con óxidos metálicos se realizaban sobre cubierta. El melado es el color natural que se obtiene de una cubierta de plomo sobre barro ocre o rosado, así el color será amarillo pajizo o miel envejecida según haya, respectivamente, menos o más hierro en la pasta. El hierro en estado de óxido férrico se transformará en óxido ferroso por la atmósfera de reducción, pigmentando de gris o negro y oscureciendo la pasta. El vidriado de plomo en contacto con la pasta gris dará verde. Suele ocasionarse siempre de forma natural cuando el barniz cubre el exterior y el interior de la pieza, existe hierro, algo de materia orgánica y carbonato cálcico en la pasta, y la cocción se produce en monococción. Las piezas vidriadas se realizaban generalmente en dos cocciones, la primera para el bizcocho y la segunda para el vidriado.

Estampillada bajo cubierta vítrea verde. Escasísimos ejemplos correspondientes a un ataifor.

Tras la cubierta estannífera la mayor innovación musulmana fue la introducción del reflejo metálico, técnica oriental que llegó a Murcia hacia fines del siglo XI o inicios del XII. No existen testimonios del uso del reflejo en el área valenciana antes de la conquista cristiana, aunque sí se han hallado ejemplares considerados de importación.

\section{LA DISTRIBUCIÓN DE SUS PRODUCCIONES}

Analizar la actividad de los talleres de cerámica a lo largo de un periodo de tiempo y en un territorio más o menos extenso, nos permite plantear cuestiones que derivan del impacto que la distribución y comercialización de sus manufacturas llegaron a ejercer sobre el área. Con todo, los datos de que disponemos en los núcleos de población de Fadrell y Safra son escasos y dispares. Ello nos lleva a sugerir que sus producciones cerámicas culinarias, en época andalusí, están destinadas a un consumo local, ajeno a los circuitos de distribución de la envergadura de las producciones de cuerda seca o de cerámica esgrafiada, mucho más ricamente decoradas.

Pero esta afirmación, si bien no es rebatible, sí que es matizable en algunos aspectos, puesto que la naturaleza de estos alfares, dedicados como se ha dicho a fabricar cerámica de uso culinario, ollas y cazuelas, complementadas por algunas otras formas destinadas a 
la contención y trasiego de líquidos, como las jarras, en algunos casos llegaría a implicar volúmenes de producción que necesariamente llegaron a superar el ámbito estrictamente local, a favor de un espacio regional más amplio.

En este sentido, deberíamos definir con mayor precisión lo que consideramos propiamente importaciones y lo que entendemos por producciones locales, puesto que hablar de productos importados en oposición a lo local a menudo genera la sensación de que entre unas y otras no existe término medio. A menudo, denominamos producciones locales aquellas manufacturas cuya distribución e intercambio puede abarcar un ámbito regional relativamente extenso. Ciertamente, la producción y distribución de cerámicas en el mundo alto medieval se relaciona de forma necesaria con el funcionamiento de las comunidades de qura. De este modo, pequeños núcleos de población, muy reducidos y diseminados por el territorio, dan respuesta a sus necesidades comerciales en circuitos reducidos y mercados locales, pero en esta jerarquización de los asentamientos que se va forjando paulatinamente, debemos constatar la existencia de una jerarquización de los centros de producción en función de sus dimensiones, su capacidad productiva y la continuidad de la producción, al menos en lo que a alfares se refiere. En este sentido, los alfares de Safra y Fadrell, suponen un exponente claro de estos centros de pequeña envergadura y producción continuada durante el final del periodo de tiempo califal, taifas y almorávide. Lo cierto es que estos talleres, con cuatro y un horno documentados respectivamente, responden a las necesidades de un mercado local entendido en un sentido estricto de impacto territorial muy reducido. Con todo, se hace necesario un proyecto de investigación más ambicioso que busque la caracterización arqueométrica de las cerámicas y que muestree las distintas áreas del territorio circundante de los alfares. Solo de esta forma podremos averiguar cómo fue la distribución real de estas artesanías en el territorio.

El ataifor que la arqueología ha podido descubrir en la excavación de Fadrell es una pieza realmente excepcional, pues ha llegado hasta nosotros en un estado de conservación excelente (Figs. 28 y 29). Además es uno de los ejemplares más destacados en el territorio de al-Andalus pues esta técnica de decoración, la cuerda seca total, solo se encuentra en un número muy reducido de objetos cerámicos. Sin embargo, ignoramos la procedencia del centro alfarero donde se fabricó, pues ninguna otra pieza con una forma o motivo similar (un ave que parece guiar un caballo) se ha encontrado en las alfarerías conocidas del sur o este peninsular.

Es un gran plato de perfil carenado, y una de las características que más llama la atención es la existencia de un segundo anillo que rodea la base anular. La pasta es de un color beige y la superficie exterior está cubierta con un tenue
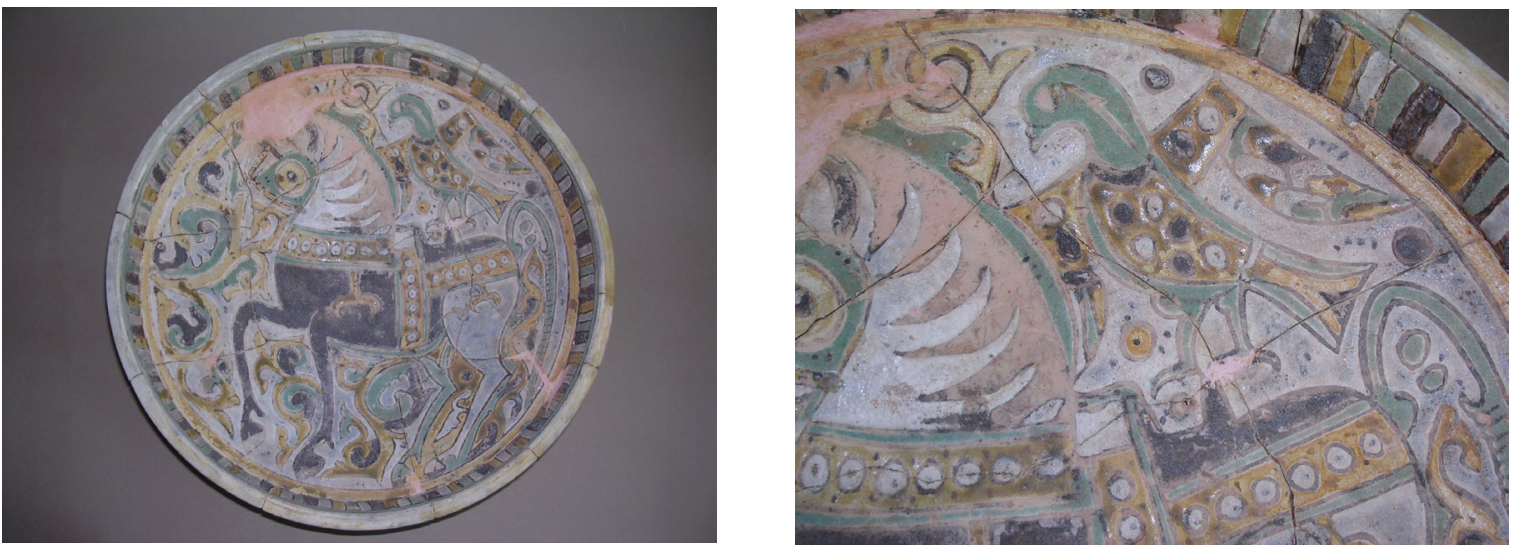

Figs. 28 y 29. Sant Jaume de Fadrell: ataifor de cuerda seca total (Fotos: SIAP). 
vidriado de plomo, entre verde y melado. La superficie interna, como se ha mencionado, se encuentra completamente vidriada mediante la técnica de la cuerda seca total.

Reproduce un programa decorativo extraordinario de época califal omeya, iconografía que perfectamente se puede encontrar en el siglo XI: un caballo peinado y ataviado con arreos, silla de color negro y colgantes, con la cola trenzada, y cabalgándolo se encuentra un ave, quizá un águila, con las alas explayadas. Los vacíos que quedan entre las figuras se rellenan por completo con motivos vegetales y donde estos no caben, se colocan algunos círculos, como en la zona de la cola del caballo y entre el ave y la cenefa. Presenta una cenefa en la parte alta, conformada por bandas verticales de colores delimitados por trazos en manganeso. En esta cenefa se alternan los mismos colores que se han utilizado en el motivo central: blanco, marrón-negro, amarillo y verde.

Gracias al estudio de P. Armengol, se han encontrado numerosos paralelos tanto dentro como fuera de la Península Ibérica, tanto respecto a las cenefas de trazos verticales, en la decoración en cuerda seca total, en la decoración en verde y marrón sobre blanco, como en cuanto a la forma del perfil (ARMENGOL, 2013). Algunas de estas semejanzas se dan en Madinat Ilbira (Medina Elvira, la Vega de Granada), Mallorca, Mértola, Ourique (Castro da Cola), l'Arrochela (Silves), Málaga, Setefilla (Lora del Río, Sevilla), Sevilla, Madinat al-Zahra, Córdoba, Almería, Ceuta, Rota (Cádiz), Murcia, Lorca, Valencia, Pisa, Sicilia, todos ellos en contextos de finales del siglo X y XI. La representación simbólica del ave sobre el caballo aparece también en unos tejidos de procedencia cordobesa que se encuentran en la parroquia de San Salvador d'Oña (Burgos) de época califal, y en diversos marfiles con representaciones de águilas provenientes de los talleres de Madinat al-Zahra y de Madinat al-Zahira, en las cercanías de Córdoba. Respecto al motivo del caballo, es muy frecuente en los marfiles califales de los talleres cordobeses y en las arquetas sículas del siglo XII, pero, sobre todo, la representación de caballos de la arqueta de Leyre de inicios del siglo XI, con el mismo atuendo que el de Sant Jaume de Fadrell.

Reproduce motivos decorativos de época califal, en el siglo X, retomados con una técnica nueva de época de los reinos taifas, la cuerda seca total. Con todo, no resulta fácil asignar una cronología concreta al plato, pudiéndose tratar de un ejemplo de permanencia de la iconografía omeya en épocas posteriores. En efecto, presenta la misma iconografía que un ataifor de Elvira (Madinat Ilbira) y que el tejido de la Parroquia de San Salvador d'Oña. El caballo guiado por un ave también coincide con los motivos zoomorfos que encontramos en los marfiles califales. También es frecuente encontrar este motivo en el siglo XI, momento en que muchos de los reinos taifas perpetúan la tradición califal como un medio de legitimación de su poder (ACIÉN, 2001). En cuanto a la época almohade, conocemos la existencia de algunas representaciones zoomorfas en la ciudad de Valencia, Denia o Málaga.

Las aves, sobre todo los halcones, aparecen relacionados generalmente con la inmortalidad, como representación en el Corán del alma que mora al Paraíso. Por su parte, el águila hace referencia al poder, a la realeza perecedera o espiritual. El caballo se encuentra ataviado y con crines y cola peinados, está preparado para ser montado, incluso para ir al combate, por lo que no hay que descartar que el tipo de caballo y el ave se relacione con el mundo de la guerra, circunstancia que le comporta una vertiente espiritual (DÉLÉRY, 2013). J. Zozaya ha propuesto una interpretación simbólica de este tipo de escenas (ZOZAYA, 2002). Para él se trataría del alma del difunto de camino al Paraíso. Se comparta o no esta interpretación, el hecho de que este motivo se repita en distintos soportes muestra que tiene un significado muy preciso dentro de la cultura andalusí.

\section{BIBLIOGRAFÍA}

ACIÉN ALMANSA, Manuel (2001): "Del estado califal a los estados taifas. La cultura material”. Actas del V Congreso de Arqueología Medieval Española. Vol. 2. Valladolid: Junta de Castilla y León. Consejería de Educación y Cultura. 
AGUAROD, Carmen; ESCUDERO, Francisco de Asís (1991): "La industria alfarera del barrio de San Pablo (siglo I-XIII)", en AA.VV. Zaragoza. Prehistoria y Arqueología. Zaragoza.

AMIGUES, François (1985): "Archéologie mediévale et islamique". Mélanges de la Casa Velázquez, 21, pp. 371-392. Madrid: Casa de Velázquez. https://doi.org/10.3406/casa.1985.2451

APARICIO SÁNCHEZ, Laura (2015): "El alfar cordobés de Ollerías y sus producciones (Siglos XII y XIII)", en Ma José GONÇALVES Susana GÓMEZ-MARTÍNEZ (coords.), Actas X Congresso Internacional A Cerâmica Medieval No Mediterrâneo (Silves-Mértola, 22-27 octubre 2012), pp. 596-603. Silves: Cámara Municipal de Silves y Campo Arqueológico de Mértola.

ARMENGOL MACHÍ, Pau (2013): "Estudi sobre la safa de corda seca total amb motius zoomorfs de Sant Jaume de Fadrell (Castelló)", en Pau ARMENGOL; Claire DÉLÉRY; Pierre GUICHARD (eds.), La safa de Sant Jaume de Fadrell, pp. 23-62. Castellón: Diputació de Castelló.

ASÓN, Irma; CARRERA, Juan Carlos; PERUA, Francisco J. (2010): "El alfar andalusí de la partida de la Rosana: arqueología de un área industrial musulmana en el Morbaiter del siglo XI (Sagunto, Valencia)". Braçal. Revista del Centre d'Estudis del Camp de Morvedre, 42, pp. 27-47.

ASÓN, Irma; CARRERA, Juan Carlos (2016): "Un asentamiento andalusí de producción de ámbito rural en la cora Balansiya. El alfar califal de la Partida de la Rosana (Valencia, España)". CLIO Arqueológica, pp. 26-52. https://doi.org/10.20891/clio.v31i2p26-52

AZUAR RUIZ, Rafael (1985): "Arqueología medieval del País Valenciano y Murcia". Arqueología del País Valenciano: panorama y perspectivas, Anejo de Lvcentvm, pp. 415-446. Alicante: Universidad de Alicante. https://doi.org/10.14198/LVCENTVM1985. Anejo.19

AZUAR RUIZ, Rafael (1989): Denia islámica: arqueología y poblamiento. Alicante: Instituto Alicantino de Cultura Juan Gil-Albert.

AZUAR RUIZ, Rafael (1998): "Alfares y Testares del Sharq Al-Andalus (siglos XII-XIII). Producción, tipología y distribución”, en José I. PADILLA; Josep M. VILA (coords.), Ceràmica Medieval i Postmedieval. Circuits productius i seqüències culturals, pp. 57-71. Barcelona: Universitat de Barcelona.

AZUAR, Rafael; BORREGO, Margarita; MARTÍ, Javier; NAVARRO, C.; PASCUAL, Josefa; SARANOVA, Rosa; BURGUERA, Vicent; GISBERT, Josep Antoni (1995): "Cerámica tardo-andalusí del País Valenciano (Primera mitad del siglo XIII)", en Actes du 5ème Colloque sur la Céramique Médiévale (Rabat 11-17 Novembre 1991), pp. 140161. Rabat: Institut National des Sciences de l'Archéologie et du Patrimoine.

AZUAR, Rafael; MARTÍ, Javier; PASCUAL, Josefa (1999): "Las cerámicas de la conquista feudal". Actas del Coloquio La cerámica andalusí. 20 años de investigación, Jaén, 15 al 17 de octubre 1997, Arqueología y Territorio Medieval, 6, pp. 279-323. Jaén: Universidad de Jaén.

AZUAR RUIZ, Rafael; MENÉNDEZ FUEYO, José Luis (1997): "El alfar islámico de la calle Curtidores-Filet de Fora de la ciudad de Elche (Alicante) (siglos XI-XIII)". Pobladores de Elche, III Época, 19, pp. 113-126. Elche.

BAZZANA, André (1990a): "La cerámica hispanomusulmana: problemas técnicos". La cerámica islámica en la ciudad de Valencia (II). Estudios. Serie Arqueológica Municipal, 9, pp. 41-60. Valencia.
BAZZANA, André (1990b): "Ensayo de tipología de la cerámica musulmana del antiguo Shara Al-Andalus". La cerámica islámica en la ciudad de Valencia (II). Estudios. Serie Arqueológica Municipal, 9, pp.143-162. Valencia.

BAZZANA, André (1996): "Inventaire du mobilier céramique. Site-refuge, grotte-sanctuaire ou abri de bergers du haut Moyen Âge? La grotte de Las Jualentejas, à Fuentes de Ayódar (Castellón)". Quaderns de Prehistòria i Arqueologia de Castelló, 17, pp. 527-550.

BENEDITO, Josep; MELCHOR, José Manuel (2018): "Las maqâbir en el entorno rural de Castellón de la Plana: balance de los descubrimientos". Quaderns de Prehistòria i Arqueologia de Castelló, 36, pp. 185-202.

BRONCANO, Santiago; ALFARO, María del Mar (1997): Los accesos a la ciudad ibérica de Meca mediante sus caminos de ruedas. TV del SIP, 92. Valencia: Diputación de Valencia.

CARMONA, Rafael; LUNA, Dolores; JIMÉNEZ, Mª́ngeles (2007): "Nuevo horno de barras de época almohade de los alfares de Madinat Baguh (Priego de Córdoba): aproximación formal a su producción cerámica”. Antiquitas, 18-19, pp. 189-214.

CLARAMONTE, Mónica; BENEDITO, Josep; MELCHOR, José Manuel (2005): "Los hornos del alfar islámico de la partida de Safra (Castellón de la Plana)". Quaderns de Prehistòria i Arqueologia de Castelló, 24, pp. 295-316.

CLARAMONTE, Mónica; BENEDITO, Josep; MELCHOR, José Manuel (2008): "El alfar andalusí y la cerámica en el yacimiento de la partida de Safra (Castellón de la Plana)". Boletín de la Sociedad Castellonense de Cultura, tomo LXXXIV, Castellón julio-diciembre 2008, pp. 437-462.

COLL CONESA, Jaume (1989): "Ceràmica i canvi cultural a la València medieval. L'Impacte de la Conquesta”. Afers, 7, pp. 125-167.

COLL CONESA, Jaume (1998): "La Ceràmica Valenciana del segles XIII al XIX. Tècniques i processos de la producció. Visió diacrònica de conjunt", en Josep I. PADILLA; Josep M. VILA(coords.), Ceràmica Medieval i Postmedieval. Circuits productius i seqüencies culturals, pp. 165-176. Barcelona: Universitat de Barcelona.

COLL CONESA, Jaume (2009): La cerámica valenciana (apuntes para una síntesis). Valencia: Asociación Valenciana de Cerámica.

COLL CONESA, Jaume (2014): "Técnica, áulica y distinción social en la cerámica medieval". Anales de Historia del Arte, 24, N Esp. Noviembre, VII Jornadas Complutenses de Arte Medieval, "Splendor". Artes suntuarias en la Edad Media hispánica, pp. 69-97. https://doi.org/10.5209/rev_ANHA.2014.48270

COLL CONESA, Jaume; GARCÍA PORRAS, Alberto (2010): "Tipología, cronología y producción de los hornos cerámicos en al-Andalus". Albisola, XLII [2009], pp. 7-24. Firenze.

COLL, Jaume; PASCUAL, Josefa; MARTí, Javier (1989): Cerámica y cambio cultural. El tránsito de la Valencia islámica a la cristiana. Madrid: Dirección General de Bellas Artes y Archivos.

COLLADO VILLALBA, Octavio; NIETO SORIANO, Emilio (2008): "Memoria de la excavación arqueológica realizada en el yacimiento Sant Jaume de Fadrell dentro del proyecto de construcción de la nueva carretera de acceso al puerto de Castellón". Boletín de la Sociedad Castellonense de Cultura, tomo LXXXIV, pp. 399-435. 
CRESPO VALERO, José Manuel; GALLARDO CARRILLO, Juan (2014): "El alfar almohade de la calle Terrer Leonés de Lorca (Murcia)". Alberca, 12, pp. 97-111.

DÉLÉRY, Claire (2013): "Algunes notes sobre la safa de corda seca total trobada a Sant Jaume de Fadrell", en Pau ARMENGOL; Claire DÉLÉRY; Pierre GUICHARD (eds.), La safa de Sant Jaume de Fadrell, pp. 63-70. Castellón: Diputació de Castelló.

ESCUDERO, Francisco de Asís (2011-2012): "Los tambores musulmanes del alfar de la calle San Pablo 95-103 de Zaragoza”. Saldvie, 11-12, pp. 147-174.

GAMO, Blanca; GUTIÉRREZ, Sonia (2009): "Los hornos de El Tolmo de Minateda (Hellín, Albacete): estructura y producción”, en Juan ZOZAYA; Manuel RETUERCE; Miguel Ángel HERVÁS; Antonio DE JUAN (eds.), Actas del VIII Congreso Internacional de Cerámica Medieval (Ciudad Real-Almagro, 27 febrero-3 marzo 2006), pp. 839848. Ciudad Real: Asociación Española de Arqueología Medieval.

GIRALT, J. (1995): "Balaguer: les fours islamiques du Pla d'Almatà (Xlè siècle)", en Le vert et le brun. De Kairouan à Avignon, céramiques du Xe au XVe siècle, pp. 22-23. Marsella.

GISBERT SANTONJA, Josep Antoni (1990): "Los hornos del alfar islámico de la avenida Montgó/calle Teulada. Casco urbano de Denia (Alicante)", en André BAZZANA; François AMIGUES (eds.), Fours de Potiers et "testares" médiévaux en Mediterranée Occidentale. Méthodes et résultats, Serie Archéologie XIII, pp. 75-92. Madrid: Casa de Velázquez.

GISBERT SANTONJA, Josep Antoni (1992): "El horno U.E. 94 del alfar islámico de la avda. Montgó-C. Teulada, 7. Denia, Alicante”. Tecnología de la cocción cerámica desde la antigüedad a nuestros días, pp. 105-120. Alicante: Asociación de Ceramología.

GISBERT SANTONJA, Josep Antoni (2003): "La producción cerámica en Daniya (Dénia) en el siglo Xl”. Tondela, pp. 61-77.

GISBERT, Josep Antoni; Azuar, Rafael; Burguera, Vicent (1991): "La producción cerámica en Daniyya. El alfar islámico de la avda. Montgó/calle Teulada (Denia, Alicante)". Cerâmica Medieval no Mediterrâneo Ocidental, pp. 247-262. Mértola: Campo arqueológico de Mértola.

GISBERT, Josep Antoni; BURGUERA, Vicent; BOLUFER, Joaquín (1992): La cerámica de Daniya -Dénia-. Alfares y ajuares domésticos de los siglos XII-XIII. Madrid: Ministerio de Cultura.

GISBERT, Josep Antoni; BURGUERA, Vicent; BOLUFER, Joaquín (1995): "El registro arqueológico cerámico de una ciudad árabe durante el primer tercio del siglo XIII. El arrabal de Daniya: "El Fortí Dénia-Alacant". Actes du 5ème Colloque sur la Céramique Médiévale (Rabat 11-17 Novembre 1991), pp. 162-177. Rabat: Institut National des Sciences de l'Archéologie et du Patrimoine.

GONZÁLEZ MARTÍ, Manuel (1952): Cerámica del Levante Español. Siglos Medievales. Vol. II y II. Barcelona: Editorial Labor.

GUICHARD, Pierre (1990): "Contexto Histórico de la Valencia Musulmana”. La cerámica islámica en la ciudad de Valencia (II). Estudios. Serie Arqueológica Municipal, 9, pp. 25-40. Valencia.

GUSI JENER, Francesc (1985): "Ermita de Nª Sa de Lledó. Campaña de urgencia 981". X Aniversario 1975-1985, Servicio de Investigaciones Arqueológicas y Prehistóricas, pp. 80-81. Castellón: Diputación Provincial.

GUSI, Francesc; OLIVER, Arturo; AGUILELLA, Gustau; CURA, Miquel (2000): SIAP XXV Aniversario 1975-2000. Castellón: Publicacions de la Diputació de Castelló.
GUTIÉRREZ LLORET, Sonia (1986): "Cerámicas comunes altomedievales: contribución al estudio del tránsito de la antigüedad al mundo paleoislámico en las comarcas meridionales del País Valenciano". Lucentum, 5, pp. 147-168. https://doi.org/10.14198/ LVCENTVM1986.5.09

GUTIÉRREZ LLORET, Sonia (1988): Cerámica común paleoandalusí del Sur de Alicante. Siglos VII-X. Alicante: Caja de Ahorros Provincial.

GUTIÉRREZ LLORET, Sonia (1990-1991): "Panes, hogazas y fogones portátiles. Dos formas cerámicas destinadas a la cocción del pan en Al-Andalus: El hornillo (tannur) y el plato (tabaq)". Lucentum, IX-X, pp. 161-175. https://doi.org/10.14198/ LVCENTVM1990-1991.9-10.10

GUTIÉRREZ LLORET, Sonia (1993): “La cerámica paleoandalusí del sureste peninsular (Tudmir): producción y distribución (siglos VII a X)". La Cerámica altomedieval en el sur de Al-Andalus, Primer encuentro de arqueología y patrimonio, pp. 37-66. Granada: Universidad de Granada.

GUTIÉRREZ LLORET, Sonia (1995): "La experiencia arqueológica en el debate sobre las transformaciones del poblamiento altomedieval en el SE de Al-Andalus: el caso de Alicante, Murcia y Albacete". Acculturazione e mutamenti. Prospettive nell'Archeologia Medievale del Mediterraneo, pp. 165-189. Firenze: Ed. All'Insegna del Giglio.

HERNÁNDEZ SOUSA, José Miguel (2014): "El urbanismo islámico en la Sevilla medieval: transformaciones e impacto en los talleres alfareros. Una aproximación al estudio de los hornos cerámicos andalusíes". Revista Historia Autónoma, 4, pp. 63-82.

LERMA ALEGRIA, José Vicente (1990): "Ensayo de cronología”. La cerámica islámica en la ciudad de Valencia (II). Estudios. Serie Arqueológica Municipal, 9, pp.163-167. Valencia.

LERMA ALEGRÍA, José Vicente et alii (1990): La cerámica islámica en la ciudad de Valencia (II). Estudios. Serie Arqueológica Municipal, 9. Valencia.

LÓPEZ ELUM, Pedro (1994): "La alimentación y sus utensilios: valor y funciones de la cerámica”. La alquería islámica en Valencia. Estudio arqueológico de Bofilla siglos XI a XIV, Valencia.

MARTíNEZ PÉREZ, Antonio y MARTíNEZ RUíZ, José Antonio. (1990): "Alzira hispano-musulmana: aproximación a su estudio". Al-Gezira, revista d'Estudis Històrics de la Ribera Alta, 6, pp. 59-143.

MOLINA EXPÓSITO, Antonio; SALINAS PLEGUEZUELO, Elena (2010): "Hornos de barras islámicos en Córdoba (España)". Albisola, XLII, pp. 45-56.

MONTMESSIN, Yves (1980): "Description analytique de la céramique commune du testar de Onda/Mas de Pere (Castellón)", Cuadernos de Prehistoria y Arqueología Castellonense, 7, pp. 243-290.

MOSTALAC CARRILLO, Antonio (1990): "Los hornos islámicos de Zaragoza", en André BAZZANA; François AMIGUES (eds.), "Fours de potiers et "testares" médiévaux en Méditerranée occidentale. Méthodes et résultats". Collection de la Casa de Velázquez, Serie Archéologie XIII, pp. 63-74. Madrid: Casa de Velázquez.

MUÑOZ LÓPEZ, Francisco (1995): "Murcie: rue San Nicolás, rue Ceferino, rue Cortes, rue Pedro de la Flor", en Le Vert et le Brun. De Kairouan à Avignon, céramiques du Xe au XVe siècle, pp. 24-27. Marsella.

NAVARRO, Julio; JIMÉNEZ, Pedro (2009): "La cerámica andalusí de Murcia a la llegada de Alfonso X”, en Alfonso Xy su época. Catálogo de la exposición celebrada en Murcia, pp. 695-704. Murcia.

PASCUAL, Josefa; ARMENGOL, Pau; GARCÍA, Isabel; ROCA, Lourdes y RUIZ, Enrique (2009): "La producción cerámica almohade en la ciudad de Valencia. El alfar de la calle Sagunto", en Juan ZOZAYA; 
Manuel RETUERCE; Miguel Ángel HERVÁS; Antonio DE JUAN (eds.) Actas del VIII Congreso Internacional de Cerámica Medieval (Ciudad Real-Almagro, 27 febrero-3 marzo 2006), pp. 355-372. Ciudad Real: Asociación Española de Arqueología Medieval.

PASCUAL, Josefa; RIBERA, Albert; ROSSELLÓ, MIQUEL; Marot, Teresa (1997): "València i el seu territori: Contexts ceràmics de la fi de la romanitat a la fi del califat (270-1031)". Arqueomediterrània. Contextos ceràmics d'època romana tardana i de l'Alta Edat Mitjana (segles IV-X). Actes Taula Rodona Badalona, novembre 1996, pp. 179-202. Barcelona: Universitat de Barcelona.

RODERO PÉREZ, Santiago (2005): "Nuevos datos para el conocimiento de la muralla islámica de la ajerquia en su tramo septentrional. A.A.P. en la plaza de la Lagunilla nº 11 (Córdoba)". Romula, 4, pp. 275-308.

ROSSER, Pablo; SOLER, Seila (2015): "Hornos cerámicos islámicos en el Tossal de les Basses (Alicante, España)", en Actas XVI Congreso de la Asociación de Ceramología (Agost, 2 a 4 de noviembre de 2012), pp. 95-122. Agost: Asociación de Ceramología.

RUIZ VAL, Enrique ; GARCIA VILLANUEVA, Isabel (1995): "Valence: les ateliers de potiers d'époque islamique du 127, rue Sagunto", en Le vert et le brun. De Kairouan à Avignon, céramiques du Xe au XVe siècle, p. 30. Marsella.

SALVATIERRA, Vicente; SERRANO, José Luis; CASTILLO, Juan CarIos; CANO, Juana; GUTIÉRREZ, Victoria (2006): "Introducción a análisis de un área artesanal califal en Marroquies Bajos (Jaén)", en Juan ZOZAYA; Manuel RETUERCE; Miguel Ángel HERVÁS; Antonio DE JUAN(eds.), Actas del VIII Congreso Internacional de Cerámica Medieval (Ciudad Real-Almagro, 27 febrero-3 marzo 2006), pp. 405418. Ciudad Real: Asociación Española de Arqueología Medieval.

SOLER FERRER, Ma Paz (1987): Historia de la cerámica valenciana, vol. 1. Valencia : Vicent García Editores.
SOLER FERRER, Mả Paz (1988): Historia de la cerámica valenciana, vol. 2. Islam y cerámica mudéjar. Valencia: Vicent García Editores.

SOLER FERRER, Ma Paz (1990): "La cerámica con decoración de cuerda seca". La cerámica islámica en la ciudad de Valencia (II). Estudios. Serie Arqueológica Municipal, 9, pp. 97-114. Valencia.

SORIANO MARTÍ, Javier (2002): Aprovechamientos históricos y situación actual del bosque en Castelló. Comité econòmic i social de la Comunitat Valenciana. Valencia: Bancaixa-Fundació Caixa Castelló.

THIRIOT, Jacques (1993): "Bibliographie du four de potier à barres d'enfournement”, en Rafael AZUAR; Javier MARTí (eds.), Actas IV Congreso de Arqueología Medieval Española (Alicante, 4-9 octubre 1993), pp. 787-798. Alicante.

TORREMOCHA SILVA, Antonio (2015): "La cerámica musulmana estampillada de los siglos XIII y XIV hallada en Algeciras". Estudios sobre Patrimonio, Cultura y Ciencias Medievales, 17, pp. 349-402.

TORRÓ ABAD, Josep (2010): “Tierras ganadas. Aterrazamiento de pendientes y desecación de marjales en la colonización cristiana del territorio valenciano", en Helena KIRCHNER (ed.), Por una arqueología agraria. Perspectivas de investigación sobre espacios de cultivo en las sociedades medievales hispánicas, BAR International Series 2062, pp. 157-172. Oxford.

TORRÓ ABAD, Josep (2013): "Presentación", en Pau ARMENGOL; Claire DÉLÉRY; Pierre GUICHARD (eds.), La safa de Sant Jaume de Fadrell, pp. 11-13. Castellón: Diputació de Castelló.

TORRES SALINAS, Francisco José (1995): "Aproximación a la arqueología islámica de Elda. Cerámica árabe de 'El Monastil' procedente de los fondos antiguos del Museo Arqueológico Municipal". Alebus, 4-5, pp. 132-152.

ZOZAYA, Juan (2002): "Iconografía omeya”, en José Luis DEL PINO (coord.), El califato de Córdoba. Córdoba: Ayuntamiento de Córdoba. 